\title{
A metabolomic approach to study the rhizodeposition in the tritrophic interaction: tomato, Pochonia clamydosporia and Meloidogyne javanica
}

\author{
N. Escudero ${ }^{1}$, F.C. Marhuenda-Egea ${ }^{2}$, R. Ibanco-Cañete ${ }^{2}$, E.A. Zavala-Gonzalez ${ }^{1,3}$, L.V. Lopez-Llorca ${ }^{1}$ \\ 1 Laboratory of Plant Pathology, Multidisciplinary Institute for Environmental Studies (MIES) Ramon Margalef, Department of Marine \\ Sciences and Applied Biology, University of Alicante, Alicante, Spain. \\ 2 Department of Agrochemistry and Biochemistry, University of Alicante, Alicante, Spain. \\ 3 Laboratory of Genetic, Investigation and Food Development Unity (UNIDA) Technological Institute of Veracruz, Veracruz. 91897 , \\ México
}

\section{ABSTRACT}

A combined chemometrics-metabolomics approach (EEM fluorescence spectroscopy, NMR and HPLC-MS) was used to analyse the rhizodeposition of the tritrophic system: tomato, the plant-parasitic nematode Meloidogyne javanica and the nematode-egg parasitic fungus Pochonia chlamydosporia. Exudates from M. javanica roots were sampled at root penetration (early) and gall development (late). EMM indicated that late root exudates from $M$. javanica treatments contained more aromatic amino acid compounds than the rest (control, P. chlamydosporia or P. chlamydosporia and M. javanica). ${ }^{1}$ HNMR showed that organic acids (acetate, lactate, malate, succinate and formic acid) and one unassigned aromatic compound (peak no. 22) were the most relevant metabolites in root exudates. Robust PCA grouped early exudates for nematode (PC1) or fungus presence (PC3). PCA found (PC1, $73.31 \%$ ) increased acetate and reduced lactate and an unassigned peak no. 22 characteristic of $M$. javanica root exudates resulting from nematode invasion and feeding. An increase of peak no. 22 (PC3, $4.82 \%$ ) characteristic of $P$. chlamydosporia exudates could be a plant "primer" defence. In late ones in PC3 $(8.73 \%)$ the presence of nematode grouped the samples. HPLC-MS determined rhizosphere fingerprints of 16 (early) and 25 (late exudates) m/z signals, respectively. Late signals were exclusive from $M$. javanica exudates confirming EEM and ${ }^{1} \mathrm{HNMR}$ results. A $235 \mathrm{~m} / \mathrm{z}$ signal reduced in $M$. javanica root exudates (early and late) could be repressed a plant defense. This metabolomic approach and other rhizosphere - omics studies could help to improve plant growth and reduce nematode damage sustainably.

Corresponding author: nuria.escudero@ua.es

Keywords: Root exudates, fluorescence spectroscopy, NMR, PARAFAC, HPLC-MS, nematophagous fungus, root-knot nematodes. 


\section{INTRODUCTION}

Plant roots exude (="rhizodeposition") an enormous range of potentially valuable low molecular weight compounds (e.g. amino acids, organic acids, sugars, phenolics, and other secondary metabolites) into the rhizosphere (Vivanco et al. 2002). The presence of such compounds in the rhizosphere led other organisms to recognize them as signals for the presence of a host plant (Koltai, 2012). The majority of the signaling between plants and other organisms is based on plant-derived chemicals, however signals are produced by the interacting organisms as well (Hirsch et al. 2003). The mechanisms used by roots to interpret the innumerable signals they receive from other roots, soil microbes, and invertebrates in the rhizosphere are largely unknown (Bais et al. 2006). Nevertheless, compounds in root exudates play important roles in these biological processes (Kneer et al. 1999, Hirsch et al. 2003).

Nematodes affect both the quality and quantity of root exudates which in turn influence the activity of both plant-pathogenic and beneficial microorganisms in the rhizosphere (Rovira et al. 1974; Van Gundy et al. 1977; Bowers et al. 1996). Roots infected by Meloidogyne incognita act as metabolic sinks, and symplastic transport of nutrients from the phloem to the feeding cell, and ultimately the nematode, result in increased rhizodeposition compared to healthy plants (Dicke and Dijkman, 2001). The nematode sedentary endoparasites cyst and root-knot nematodes (Heterodera/Globodera and Meloidogyne spp., respectively) exhibit complex and intimate associations with their host plant, which involve reciprocal signaling between host and parasite. With a few exceptions, the nature of the signaling molecules remains unknown (Hirsch et al. 2003). Sedentary plant-parasitic nematodes, such as Meloidogyne spp., have co-evolved with their hosts to develop mechanisms for successful root invasion. Nematodes produce a large repertoire of effectors including proteins, peptides and other small molecules (Haegeman et al. 2012). How and what triggers the secretion of specific effectors in different 

50

host tissues and cells at critical time-points in their parasitic process remains a mystery (Mitchum et al. 2013). M. javanica perceives root signals prior to physical contact and plant penetration. Root exudates play a major role in the attraction of plant parasitic nematodes to their host roots (Teillet et al. 2013). However, the particular plant stimuli involved in key stages of the plant-nematode interaction have not yet been clearly identified (Dutta et al. 2012). Plant root exudates chemicals originating from sites of previous penetration can influence nematode behavior, and a number of plant compounds, some present in root exudates, have been shown either to attract nematodes to the roots or to result in repellence, motility inhibition, or even death (Rao et al. 1996; Zhao, 1999; Wuyts et al. 2006; Curtis et al. 2009). Rhizosphere microbiota also influences nematode biology. To this respect, penetration by M. incognita juveniles was reduced in mycorrhizal tomato roots, partly due to the negative effect of root exudates on nematode motility (Vos et al. 2012). Dababat and Sikora (2007) showed that nematode invasion of tomato was reduced significantly when roots were colonized by the endophyte Fusarium oxysporum FO162.

The nematophagous fungus Pochonia chlamydosporia (=Verticillium chlamydosporium) has been studied as a biocontrol agent of root-knot (Meloidogyne spp.), false root-knot (Nacobbus spp.) and cyst (Heterodera spp. and Globodera spp.) nematodes (De Leij and Kerry 1991; Atkins et al. 2003; Tzortzakakis 2007). $P$. chlamydosporia is also an antagonist of economically important phytopathogenic fungi including root pathogens (Monfort et al. 2005; Leinhos and Buchenauer, 1992). This fungus is distributed worldwide and can survive as a saprotroph in the absence of the nematode host. Some isolates of this fungus are rhizosphere competent (Bourne et al. 1996) as well as easily cultivated in vitro (Bourne et al. 1999) and can produce chlamydospores resistant to stress. The fungus can colonize endophytically roots of host plants (e.g. Gramineae and Solanaceae) promoting their growth (Macia-Vicente et al. 2009, Escudero and Lopez-Llorca, 2012). 
Metabolomics, the study of all metabolites in a given biological system (Dixon and Strack, 2003) can detect putative signaling compounds (especially those of low molecular weight) present in the tritrophic interactions root-nematode-biocontrol agent. A compressive detection of these compounds and their dynamics would require diverse complementary analytical technologies (Moco et al. 2006). There are two approaches to study the production of small molecules in biological systems. The most common, metabolite profiling, is the analysis of small numbers of known metabolites in specific compound classes (e.g. sugars, amino acids or phenolics). At the other extreme, metabolic fingerprinting detects many compounds but their structures are rarely identified (Gibon et al. 2012). In this work we have followed a mixed approach (profiling/fingerprinting) since the response of tomato roots to root-knot nematodes/nematophagous fungi (P. chlamydosporia) is largely unknown.

Fluorescence excitation-emission matrix (EEM) spectroscopy is a sensitive and fast technique. It has been applied to the study of solved organic matter (SOM) from different sources (Coble, 1996; Mobed et al. 1996; Parlanti et al. 2000; Provenzano et al. 2001; Baker, 2002; Chen et al. 2003; Sierra et al. 2005, Hudson et al. 2007, Marhuenda-Egea et al. 2007). Frequently, it is not possible to obtain EEM spectra with isolated peaks due to the heterogeneity of SOM (Chen et al. 2003). Manual "peak picking" of the EEM fluorescence spectra of SOM often suggests the presence of several fluorophores, each one characterized by an Excitation/Emision wavelength pair (Marhuenda-Egea et al. 2007). Parallel factor analysis (PARAFAC) has been applied to EEM fluorescence spectra to model the suite of complex EEM landscapes into chemically meaningful spectral and concentration components (Bro, 1997; Andersen and Bro, 2003).

High resolution Nuclear Magnetic Resonance ${ }^{1} \mathrm{H}$ NMR spectroscopy is a non-destructive quantitative technique useful in metabolomic studies (Bothwell and Griffin, 2011). However, NMR, involves the detection of very small transitions in the nuclei of atoms, comparable with the thermal energy in the 
system, it is limited by low detection range (5-10 $\mu \mathrm{M})$ (Heather et al. 2013). Some metabolites are

hidden in NMR spectra if they are co-resonant with higher concentration metabolites (i.e. resonances 


\section{MATERIALS AND METHODS}

\subsection{Fungi, nematodes and plants}

The nematode-egg fungal parasite $P$. chlamydosporia, isolate Pc123 (ATCC No. MYA-4875), used in this work was obtained from Heterodera avenae infected eggs in SW Spain (Olivares-Bernabeu and Lopez-Llorca, 2002). Root-knot nematode (RKN) M. javanica was obtained from a field population (Escudero and Lopez-Llorca, 2012) and maintained in susceptible tomato plants. Nematode egg masses were dissected from RKN-infested roots and stored at $4^{\circ} \mathrm{C}$. Egg masses were hand-picked and surfacesterilized as in McClure et al. (1973) with slight modifications. M. javanica second-stage juveniles (J2) were hatched from surface-sterilized eggs at $28^{\circ} \mathrm{C}$ in the dark. Tomato plants (Solanum lycopersicum Mill. cv Marglobe) were used in all experiments.

\subsection{Inoculation of tomato seedlings with $P$. chlamydosporia and $M$. javanica}

Surface-sterilized tomato seeds were plated on germination medium and incubated at $25^{\circ} \mathrm{C}$ in the dark for 7 days (Bordallo et al. 2002). Tomato seedlings free from contaminants were either inoculated for 3 days with $P$. chlamydosporia or were left uninoculated (controls) (20 each). They were then placed in $150 \mathrm{ml}$ polypropylene sterile containers (VWR) each containing $70 \mathrm{~cm}^{3}$ of sterilized sand and $23 \mathrm{ml}$ of 1/10 Gamborg's basal mixture (Sigma) and incubated for 15 days at $25{ }^{\circ} \mathrm{C}$ under a $16 \mathrm{~h}$ light $/ 8 \mathrm{~h}$ dark photoperiod. Twenty five-day-old tomato plants, growing on sterilized sand as described above, were either left untreated or inoculated with $100 \mathrm{M}$. javanica juveniles (J2) per plant. Seven days later, a subsample of 10 plants per treatment was taken. The remaining plants (10 per treatment) were kept for a total period of 60 days (Escudero and Lopez-Llorca, 2012). Abbreviations of all treatments are as follows: tomato plants (To), tomato plants inoculated with $P$. chlamydosporia (To+Pc), tomato plants inoculated with $M$. javanica $(\mathrm{To}+\mathrm{RKN})$ and tomato plants inoculated with $P$. chlamydosporia and $M$. 


\subsection{Nuclear magnetic resonance (NMR) spectroscopy}

Root exudates $(20 \mathrm{ml})$ were lyophilized and resuspended in $1 \mathrm{ml}$ of ultrapure water (Millipore). Five hundred and fifty $\mu \mathrm{L}$ of these root exudates concentrated were placed in a $5 \mathrm{~mm}$ NMR tube with $50 \mu \mathrm{L}$ 


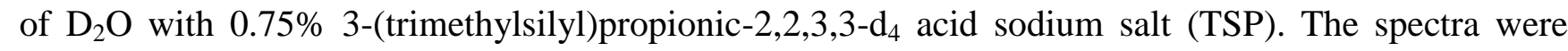
referenced to TSP at $0.00 \mathrm{ppm}$.

All ${ }^{1} \mathrm{H}$ NMR experiments were performed on a Bruker Avance $400 \mathrm{MHz}$ equipped with a $5 \mathrm{~mm}{ }^{1} \mathrm{H}-$ BB- ${ }^{13} \mathrm{C}$ TBI probe with an actively shielded Z-gradient. ${ }^{1} \mathrm{D}$ solution state ${ }^{1} \mathrm{H}$ NMR experiments were acquired with a recycle delay of $2 \mathrm{~s}, 32,768$ time domain points and with $2.556 \mathrm{~s}$ of acquisition time.

The number of scans was 1024 and the experiment was carried out at $298^{\circ} \mathrm{K}$. Spectra were apodized by multiplication with an exponential decay producing a $0.3 \mathrm{~Hz}$ line broadening in the transformed spectrum. ${ }^{1} \mathrm{H}$ chemical shifts were reference internally to the sodium trimethylsilyl $\left[2,2,3,3-{ }^{2} \mathrm{H}_{4}\right]$ propionate at $\delta 0.00$. The ${ }^{1} \mathrm{H}$ NMR spectra were normalized and reduced to ASCII files using customwritten MestreC software (Santiago de Compostela, Spain) and aligned using icoshift (version 1.0; available at www.models.kvl.dk) (Savorani et al. 2010). All ${ }^{1} \mathrm{H}$ NMR spectra processing was performed in MATLAB (The MathWorks, Natick, MA).

\subsection{High performance liquid chromatography HPLC-ESI-MS spectroscopy} 36 37 3187 39

The HPLC-ESI-MS analysis was performed with the Agilent (Santa Clara, CA) 1100 series HPLC instrument. The HPLC system was coupled with the Agilent 1100 Series LC/MSD Trap SL. The mass spectrometer was operated in the positive and negative ESI modes, and the ion spray voltage was set at $4 \mathrm{kV}$. Nitrogen was used as the sheath gas (30 psi), and the ion transfer capillary heated to $350{ }^{\circ} \mathrm{C}$. Injections were carried out using an HTC Pal autosampler (CTC Analytics, Zwingen, Switzerland) equipped with a $20 \mu \mathrm{L}$ sample loop. The tomato root exudates were infused into the flow of the HPLC system $(10 \mu \mathrm{L})$ through a T connection, under the following conditions: flow rate of the HPLC system, $0.3 \mathrm{ml} / \mathrm{min}(30 \mathrm{mM}$ ammonium acetate and $5 \%$ acetic acid at a ratio of 12.5:87.5, $\mathrm{pH} 2.5$, solvent $\mathrm{A})$. The LC separations were carried out with Phenomenex (Torrance, CA) Luna 5 $\mu$ SCX 100 A $^{\circ}$ column, $150 \mathrm{~mm}$ X $2.0 \mathrm{~mm}$ internal diameter, at $25^{\circ} \mathrm{C}$. For the elution of the metabolites, an isocratic step was 
programmed with solvent A for 15 minutes. The overall flow rate was adjusted to $0.3 \mathrm{ml} / \mathrm{min}$. Before

use, the new SCX column was flushed overnight with $150 \mathrm{mM}$ of ammonium acetate solution. The ranges of scans were $70-275$ and $250-500 \mathrm{~m} / \mathrm{z}$ to improve sensitivity. The raw data was transformed as explained by Marhuenda-Egea et al. (2013).

\subsection{Statistical analysis}

EEM Fluorescence data was analyzed by PARAFAC, as described above, and the contribution of the component 1 and component 2 analyzed by ANOVA tests. The level of significance in all cases was 95\%. All statistical analyses were performed with R version 2.11.1 (R Development Core Team, 2009).

After ${ }^{1} \mathrm{H}$ NMR and HPLC-MS data processing (Marhuenda-Egea et al. 2013) we chose an unsupervised method such as the robust principal component analysis (ROBPCA), instead of a Partial Least Square (PLS) regression model due to our sample size. It was applied to reduce the data dimension (Verboven and Hubert, 2005). Using a classical PCA there was the possibility that the first components could be highly attracted by outlayers and would not give a good low-dimensional representation of data (Verboven and Hubert, 2005). Putative outlayer data were detected using diagnostic plots and eliminated from the final analyses when were present (Verboven and Hubert, 2005). This multivariate data analysis ROBPCA was carried out using the LIBRA toolbox (available at http://wis.kuleuven.be/stat/robust/software).

\section{RESULTS}

\subsection{EEM fluorescence spectra Excitation-Emission and PARAFAC modeling of tomato root} exudates 
Contour Excitation-emission matrix (EEM) spectra of tomato root exudates of all treatments are shown

in Figure 1. The spectra indicated the presence of several fluorophores, characterized by Ex/Em wavelength pairs. Parallel Factor Analysis (PARAFAC) resolved EEM spectra into chemically meaningful spectra components. PARAFAC model components were calculated. CONCORDIA values were $97.1,58.5$ and 5.6 for models with two, three and four components respectively. Therefore, to analyze the fluorescence data, a two components model was used (Fig 1). Component 1 included three putative fluorophores with Ex/Em wavelength pairs of $315 / 438 \mathrm{~nm}, 265 / 438 \mathrm{~nm}$ and 240/438 nm corresponding to high molecular weight phenolics similar to fulvic and humic acids (Bertoncini et al. 2005; Sierra et al. 2005; Ohno and Bro, 2006). Component 2 included two putative fluorophores with Ex/Em wavelength pairs of 280/336 nm and 230/336 nm corresponding to aromatic amino acids such as Tryptophan and Tyrosine (Chen et al. 2003; Marhuenda-Egea et al. 2007). The intensity of component 1 for all samples was higher than that of component 2 .

EMM spectra of early tomato root exudates were similar irrespective of the treatment (Figs 1a-d). Slight differences were found only in component 1 , but no differences were found for component 2. On the contrary, differences in late tomato root exudates EEM spectra for component 2 were apparent, especially in root exudates from plants inoculated with RKN (Figs 1e-h, online resource 1). Statistical analyses ( $\mathrm{p}$-value $<0.05)$ showed that $\mathrm{To}+\mathrm{Mj}$ and $\mathrm{To}+\mathrm{Pc}+\mathrm{Mj}$ root exudates significantly contained more compounds with aromatic amino acids than To and To+Pc root exudates (online resource 2). Conversely, when only the nematophagous fungus ( $P$. chlamydosporia) was in the rhizosphere, the intensity of component 2 was the lowest (Fig 1f), although this difference was not statistically significant (online resource 2). Regarding evolution of both components, over time component 1 remained virtually unchanged. On the contrary, component 2 increased from early to late exudates to different extents for each treatment with a maximum of 5 fold for $M$. javanica treatments (Online resource 2). 


\subsection{Nuclear magnetic resonance (NMR) spectroscopy of tomato root exudates}

Representative ${ }^{1} \mathrm{H}$ NMR profiles from To and To+Mj treatments are shown in Figure 2. The dataset contained 23 peaks. Ten of these were included in the organic-acid/amino acids region (I), eleven in the sugar/polyalcohol region (II) and two in the phenolic/aromatic region (III). Some ${ }^{1} \mathrm{H}$ NMR peaks could be identified after $2 \mathrm{D}-\mathrm{NMR}$ and using ${ }^{1} \mathrm{H}$ NMR spectra from pure compounds (Table 1). A visual inspection of the profiles indicated that acetate (peak no. 5), lactate (peaks no.2 and no.12), malate (peak no.7), succinate (peak no.8), formic acid (peak no. 23) and an unassigned aromatic compound (peak no.22) were observed in early root exudates.

ROBPCA was used to provide an overview of sample grouping between treatments. The first principal component $(\mathrm{PC} 1)$ of the score plot from early root exudates explained ca. $73 \%$ of the total variability and clearly separated root exudates, with M. javanica (on the negative side) from the rest (on the positive side, Fig 3a). The second (PC2) and third (PC3) components explained $7.99 \%$ and $4.82 \%$ of sample variability respectively (Fig 3b-c). The PC3 score plot illustrated the separation of samples due to the presence of the nematophagous fungus, P. chlamydosporia (Fig 3b).

Loading analysis (Fig 3c) suggested that the metabolites contributing most to this separation along PC1 were dominated by the acetate peak (no. 5), one unassigned peak in the aromatic region (no. 22), lactate (peak no. 2) and the sugars/polyalcohol region. PC2 loading (Fig 3d) was dominated by lactate (peak no. 2), malate (peak no. 7), several peaks in the sugar/polyalcohol region, and the unassigned peak no. 22. Finally, the loading for PC3 (Fig 3e) was dominated by the unassigned peak no. 22.

For late root exudates score plot of PC1 explained ca. $65.9 \%$ of total variability (Fig 4a). In this case, PC2 and PC3 explained $16.9 \%$ and $8.73 \%$ respectively of the variability of samples (Fig 4a-b). Only in the case of PC3, samples were grouped by the presence of nematodes (negative side, Fig 4b). 
PC1 loadings (Fig 4c) showed that major differences in the samples were again due to acetate (peak no.

5). Differences in PC2 loading (Fig 4d) were due to signals in the sugars/polyalcohol region and formic

7 44

acid and peak no. 22 in the phenolic/aromatic region. In PC3 (Fig 4e) loading showed variations many

signals due to the presence of the nematode in the roots. Differences were found in the amino acid/organic acid and sugar/polyalcohol regions, and a faint increase in signals intensity was found in the phenolic/aromatic region (between 6.5 and $7.5 \mathrm{ppm}$ ) and more specifically formic acid and peak no. 22 explained the difference. This result can be correlated with the increase of signals from component 2 found in PARAFAC analysis of EEM Fluorescence data shown in Fig 1e-f.

\subsection{HPLC-MS of tomato root exudates}

Figures 5 and 6 show HPLC-MS score plots and loadings for PC1 of early and late tomato root exudates for all treatments, respectively. Score plots indicated that root exudates were mostly grouped by the presence of $M$. javanica. PC1 from samples explained ca. 50-60\% of the variance for early root exudates and ca. $90 \%$ or more for late ones. Loadings of $\mathrm{PC} 1$ displayed different $\mathrm{m} / \mathrm{z}$ signals characteristic of root exudates and the most significant values of $\mathrm{m} / \mathrm{z}$ signals were included in the loadings.

Signals were quantified by determining the area under the peaks, $\mathrm{m} / \mathrm{z}$ signals with intensities significantly different $(\mathrm{p}<0.05)$ from those of uninoculated tomato exudates are shown in Table 2 (Online resource). Those $\mathrm{m} / \mathrm{z}$ signals were classified using Venn diagrams (Figure 7). When all $\mathrm{m} / \mathrm{z}$ signals were analyzed early root exudates appeared more variable than late ones. In the former, $16 \mathrm{~m} / \mathrm{z}$ signals were detected with significant varied expression in the rhizosphere, respect to 25 in the latter. In early root exudates five $\mathrm{m} / \mathrm{z}$ signals $(130,235,235 \mathrm{~b}, 263$ and $343.9 \mathrm{~m} / \mathrm{z})$ were found associated with the presence of M. javanica (Fig 7a). Two of those $\mathrm{m} / \mathrm{z}$ signals (130b and 263) were found associated with the presence of both $M$. javanica and $P$. chlamdydosporia in the rhizosphere. Only one $\mathrm{m} / \mathrm{z}$ signal 
$(174.8 \mathrm{~m} / \mathrm{z})$ was found exclusive of the presence of the $P$. chlamydosporia and was only present in early exudates. On the contrary, all $\mathrm{m} / \mathrm{z}$ signals in late root exudates were associated with the presence of $M$. javanica (Fig 7d). Two of those (235 and $235 \mathrm{~b} \mathrm{~m} / \mathrm{z}$ signals) were also present in early root

exudates. Regarding intensity in early root exudates most $(56 \%) \mathrm{m} / \mathrm{z}$ signals were reduced respect to uninoculated roots. On the contrary, in late root exudates most $(64 \%) \mathrm{m} / \mathrm{z}$ signals in treatments were increased.

\section{DISCUSSION}

In this work we have used a metabolomics approach to analyze the rhizodeposition of tomato plants infected by root-knot nematodes (M. javanica) and inoculated with a nematophagous fungus ( $P$. chlamydosporia). This approach included three strategies (EMM, NMR \& HPLC-MS) for analysis combined with chemometric tools. The presence of the root-knot nematode $M$. javanica in the rhizosphere was the factor which influenced most the metabolomic profile of tomato root exudates.

Plant parasitic nematodes (PPN) manipulate plant development pathways (Gheysen and Mitchum, 2011). Therefore nematodes respond to root metabolites and in turn modify rhizodeposition (Koltai et al. 2012; Teixeira-Machado et al. 2012). Also PPN infestation may influence the chemical profile of the root exudates (Back et al. 2010). This is specially true at the end of their life cycle when root knot nematodes enhance rhizodeposition making roots "leaky" (Bourne et al. 1996).

In our study, sampling times were established to include in $M$. javanica infested roots - juvenile root penetration (early exudates) and gall formation and development (late exudates). When early root exudates were analyzed fluorometrically PCA could not group them by treatment (eg. nematode, fungus or both). However PC1 of NMR data indicated that early exudates from nematode infested roots were characterized by a large increase in acetate, a reduction in lactate and an unassigned aromatic compound peak no. 22 content. This metabolomic profile would illustrate the rhizodeposition 
corresponding to nematode root recognition and penetration and early feeding site development

(Hofmann, 2010). EEM fluorescence spectra of late exudates from roots infested with RKN (inoculated

or not with with P. chlamydosporia) showed an increase in aromatic compounds (Chen et al. 2003)

respect to roots with no RKN. These could either be peptides including aromatic amino acids (such as Tryptophan and Tyrosine) or the amino acids themselves. Aromatic amino acids have been previously described in tomato root exudates (Simons et al. 1997, Vivanco et al. 2002). The role of these aromatic compounds is unknown. They could be plant defenses since amino acids in root exudates have been found to inhibit egg-hach and juvenile root penetration of the root-knot nematodes $M$. javanica (Tanda et al. 1989). These putative tomato defenses could not, in our case, have affected nematodes hatching/invasion since they were increased in late root exudates during gall formation and maturation. The reason for this would be the tomato cv. used in this study highly susceptible to RKN (Bendezu, 2004). In a metabolomics study of the cyst nematode Heterodera schachtii in Arabidopsis infested roots, amino acids were increased in syncitia (root feeding sites) induced by the nematode (Hofmann et al. 2010). We could identified in a ${ }^{1}$ HNMR profile compounds as acetate, malate, lactate, succinate and formic acid some of them were reported previously in tomato root exudates (Kamilova et al. 2006; Zhang et al. 2009; Teixeira-Machado, 2012; Hage-Ahmed et al. 2013). Amino acids, glucose, malate, and other metabolites detected in our study by ${ }^{1} \mathrm{H}$ NMR, are probably essential for nematode nutrition (Baldacci-Cresp, et al. 2012). Alternatively, aromatic amino acids could be part of plant peptide hormones (CLEs), which regulate wide variety of developmental processes. CLEs have been found to be mimicked by nematode efectors (Gheysen and Mitchum, 2011). Therefore, the increase in fluorescent signals corresponding to aromatic amino acids could be due to CLEs from plant or nematode origin involved in root morphological changes associated with gall development and maturation. Using ${ }^{1}$ HNMR an unassigned peak (no. 22) corresponding to aromatic compound had reduced expression in early and late RKN infected roots exudates. These could be putative tomato defense metabolites suppressed by $M$. javanica in a susceptible tomato cultivar. To this respect, RKN 
are known to either supress host defences signalling or are able to avoid host recognition (Goto et al. 2013).

A large increase (more than five fold) in the unassigned aromatic compound, (peak 22), was detected by ${ }^{1} \mathrm{HNMR}$ in Pochonia chlamydosporia colonized roots. This increase in a putative defense compound (see above) could be an evidence of "priming" or induction of plant defenses by beneficial microbes by the nematophagous fungus (Conrath et al. 2006). To this respect several biocontrol agents including bacteria and fungal endophytes (Shovesh et al. 2010) are known to induce priming. Pochonia chlamydosporia is a facultative endophyte, found to elicit in several plants including tomato local (e.g. cell wall papilae) as well as systemic plant defense responses (phenolics) (Bordallo et al. 2002; MaciaVicente et al. 2009; Escudero and Lopez-Llorca et al. 2012). The latter could contribute to a $P$. chlamydosporia specific tomato rhizodeposition profile.

In this work, we used an HPLC-MS approach to generate a metabolomics fingerprint (Gibon et al. 2012) of the rhizodeposition in the tritrophic system: tomato, $M$. javanica and $P$. chlamydosporia. The complex data set generated was classified by treatments using a Venn diagram approach. This useful technique commonly used in other -omics approach has not been fully exploited yet with metabolomics data (Patti et al. 2012).

The HPLC-MS fingerprint of early rhizodeposition in tomato roots included less (16) $\mathrm{m} / \mathrm{z}$ signals that in late (25) exudates. Besides, early $\mathrm{m} / \mathrm{z}$ signals could be associated to $M$. javanica or $P$. chlamydosporia, whereas in late root exudates all $\mathrm{m} / \mathrm{z}$ signals were associated with $M$. javanica in the roots. This confirm previous finding with the other two analytical tools (EEM and NMR) used which detected M. javanica as the main factor for classifying root exudates.

As already suggested metabolites ( $\mathrm{m} / \mathrm{z}$ signals) with reduced expression in $M$. javanica derived exudates, could be suppress plant defences. In our study, a $235 \mathrm{~m} / \mathrm{z}$ signal was reduced in $M$. javanica 
exudates (both early and late) respect to control tomato exudates. This could be a strong candidate for a nematode suppress plant defence which should be identified and studied in futures works (Dutta et al. 2012). Only a $174.8 \mathrm{~m} / \mathrm{z}$ signal could be associated and increased with the presence of $P$. chlamydosporia in the rhizosphere. Although the mass coincides with date of indol-3-acetic-acetic acid our efforts to confirm this by MS were unsuccessful (not shown). However, detection of tryptophan a precursor of AIA in this study and root growth promotion of $P$. chlamydosporia (Escudero and LopezLlorca, 2012) would support this hypothesis. Futures studies should clarified the presence of auxin in the rhizodeposition in this tritrophic system.

\section{ACKNOWLEDGMENTS}

This research was funded by the Spanish Ministry of Science and Innovation Grants AGL 200800716/AGR, AGL 2011-29297 and with a grant from University of Alicante to N. Escudero (UAFPU2011). The authors want to thank Mr. Federico Lopez Moya his collaboration in the development and discussion of Venn Diagrams.

\section{REFERENCES}


Atkins, S., Hidalgo-Diaz, L., Kalisz, H., Mauchline, T. H., Hirsch, P. R. \& Kerry, B.R. (2003). Development of a new management strategy for the control of root-knot nematodes (Meloidogyne spp.) in organic vegeTable production. Pest Management Science 59, 183-189.

Andersen, C. M. \& Bro, R., (2003). Practical aspects of PARAFAC modeling of fluorescence excitation-emission data. Journal Chemometrics, 17(4), 200-215.

Back, M., Jenkinson, P., Deliopoulos T. \& Haydock, P. (2010). Modifications in the potato rhizosphere during infestations of Globodera rostochiensis and subsequent effects on the growth of Rhizoctonia solani. European Journal of Plant Pathology 128(4), 459-471.

Baker, A. (2002). Fluorescence properties of some farm wastes: implications for water quality monitoring. Water Research, 36(1), 189-195.

Bais, H.P., Weir, T.L., Perry, L.G., Gilroy, S. \& Vivanco, J.M. (2006). The Role of Root Exudates in Rhizosphere Interactions with Plants and Other Organisms. Annual Review of Plant Biology 57, 233-266.

Baldacci-Cresp, F., Chan, C., Maucourt M., Deborde C., Hopkins J., Lecomte P., Bernillon S., Brouquisse R., Moing, A., Abad, P., Hérouart, D., Puppo, A., Favery, B. \& Frendo., P. (2012). (Homo)glutathione Deficiency Impairs Root-knot Nematode Development in Medicago truncatula. PLoS Pathog 8 (1), 1002471.

Bendezu, I. F. (2004). Detection of the tomato mi 1.2 gene by PCR using non-organic DNA purification. Nematropica, 34(1), 23-30.

Bertoncini, E.I., D’orazio, V., Senesi, N. \& Mattiazzo, M. E., (2005). Fluorescence analysis of humic and fulvic acids from two Brazilian oxisols as affected by biosolid amendment. Analytical and Bioanalytical Chemistry 381(6), 1281-1288

Bordallo, J. J., López-Llorca, L. V., Jansson, H. B., Salinas, J., Persmark, L., \& Asensio, L. (2002). Colonization of plant roots by egg-parasitic and nematode-trapping fungi. New Phytologist 154(2), 491-499.

Bourne, J. M., Kerry, B. R. \& De Leij, F. A. A. M., (1996). The importance of the host plant on the interaction between root-knot nematodes (Meloidogyne spp.) and the nematophagous fungus, Verticillium chlamydosporium Goddard. Biocontrol Science and Technology 6, 539-548. 
Bourne, J. M., Kerry, B. R., Galloway, J., Smith, C. \& Marchese, G., (1999). Evaluation of application techniques and materials for the production of Verticillium chlamydosporium in experiments to control root-knot nematodes in glasshouse and field trials. Journal of Nematology 9, 153-162.

Bothwell, J. H. \& Griffin, J. L. (2011). An introduction to biological nuclear magnetic resonance spectroscopy. Biol Rev Camb Philos Soc, 86, 493-510.

Bowers, J. H., Nameth, S. T., Riedel, R. M. \& Rowe, R. C. (1996). Infection and colonization of potato roots by Verticillium dahliae as affected by Pratylenchus penetrans and $P$. crenatus. Phytopathology 86, 614-21

Bro, R. (1997). PARAFAC: Tutorial and applications. Chemom. Intell. Lab. Syst. 38(2), 149-171.

Chen, W., Westerhoff, P., Leenheer, J. A. \& Booksh, K. (2003). Fluorescence excitation-emission matrix regional integration to quantify spectra for dissolved organic matter. Environ. Sci. Technol. 37(24), 5701-5710.

Coble, P. G. (1996). Characterization of marine and terrestrial DOM in seawater using excitationemission matrix spectroscopy. Mar. Chem. 51(4), 325-346.

Conrath, U, Beckers, G. J. M, Flors, V., García-Agustín, P., Jakab, G., Mauch, F., Newman, M. A., Pieterse, C. M. J, Poinssot, B, Pozo, M. J., Pugin, A., Schaffrath, U, Ton, J, Wendehenne, D. Zimmerli, L. \& Mauch-Mani, B. (2006). Priming: Getting Ready for Battle. MPMI 19 (10), 1062-1071.

Curtis, R. H. C., Robinson, A. F. \& Perry, R. N. (2009). Hatch and host location. In: Perry, R.N., Moens, M. and Starr, J. (Eds). Root-knot nematodes. Wallingford, UK, CABI Publishing, pp. 139-162.

Dababat, A.E.F.A. \& Sikora R.A (2007). Influence of the mutualistic endophyte Fusarium oxysporum 162 on Meloidogyne incognita attraction and invasion. Nematology 9 (6), 771-776.

De Leij F. A. A. M. \& Kerry, B. R., (1991). The nematophagous fungus, Verticillium chlamydosporium, as a biological control agent for Meloidogyne arenaria. Revue de Nematologie 14, 157-194.

Dicke, M. \& Dijkman, H. (2001). Within-plant circulation of systemic elicitor of induced defence and release from roots of elicitor that affects neighbouring plants. Biochem. Syst.Ecol. 29,. 1075-87.

Dixon, R.A. \& Strack, D. (2003). Phytochemistry meets genome analysis, and beyond. Phytochemistry $62,815-816$. 
Dutta, T., Powers, S., Gaur, H., Birkett, M. \& Curtis, R. (2012). Effect of small lipophilic molecules in tomato and rice root exudates on the behaviour of Meloidogyne incognita and M. graminicola. Nematology 14 (3), 09-320.

Escudero, N. \& Lopez-Llorca, L. V. (2012). Effects on plant growth and root-knot nematode infection of an endophytic GFP transformant of the nematophagous fungus Pochonia chlamydosporia Symbiosis 57, 33-42.

Gheysen, G. \& Mitchum, M. G. (2011). How nematodes manipulate plant development pathways for infection. Current Opinion in Plant Biology 14 (4), 415-421.

Gibon, Y., Rolin, D., Deborde, C., Bernillon, S. \& Moing, A. (2012). "New Opportunities in Metabolomics and Biochemical Phenotyping for Plant Systems Biology". In Biochemistry, Genetics and Molecular Biology. Metabolomics.

Goto, D. B., Miyazawa, H., Mar, J. C. \& Sato, M. (2013). Not to be suppressed? Rethinking the host response at a root-parasite interface. Plant Science, 213: 9-17.

Haegeman, A., Mantelin, S., Jones, J.T. \& Gheysen, G. (2012). Functional roles of effectors of plantparasitic nematodes. Gene 492, 19-31.

Hage-Ahmed, K., Moyses, A., Voglgruber, A., Hadacek, F. \& Steinkellner, S. (2013). Alterations in Root Exudation of Intercropped Tomato Mediated by the Arbuscular Mycorrhizal Fungus Glomus mosseaeand the Soilborne Pathogen Fusarium oxysporumf. sp. lycopersici. Journal of Phytopathology.

Heather, L. C, Wang, X. West J. A \& Griffin J. L. (2013). A practical guide to metabolomic profiling as a discovery tool for human heart disease. Journal of Molecular and Cellular Cardiology 5, 2-11.

Hirsch, A.M., Bauer, W.D., Bird, D.M., Cullimore, J., Tyler, B. \& Yoder, J.I. (2003). Molecular signals and receptors: controlling rhizosphere interactions between plants and other organisms. Ecology $84,858-68$.

Hofmann J, Ashry AENE, Anwar S, Erban A, Kopka J, Grundler F (2010). Metabolic profiling reveals local and systemic responses of host plants to nematode parasitism. The Plant Journal 62, 1058-1071.

Hudson, N. J., Baker, A. \& Reynolds, D. (2007). Fluorescence analysis of dissolved organic matter in natural, waste and polluted waters - a review. River Res. Appl. 23(6), 631-649. 
Kamilova, F., Kravchenko, L. V., Shaposhnikov, A. I., Azarova, T., Makarova, N., Lugtenberg, B. (2006). Organic Acids, Sugars, and L-Tryptophane in Exudates of Vegetables Growing on Stonewool and Their Effects on Activities of Rhizosphere Bacteria. MPMI 19 (3), 250-256

Kneer, R., Poulev, A. A., Olesinski, A., \& Raskin, I. (1999). Characterization of the elicitor-induced biosynthesis and secretion of genistein from roots of lupinus luteus L. Journal of Experimental Botany, 50(339), 1553-1559.

Koltai, H., R. Matusova, and Y. Kapulnik. (2012). Strigolactones in root exudates as a signal in symbiotic and parasitic interactions. Pp. 49-73 In: J. M. Vivanco and F. Baluška (eds.), Secretions and Exudates in Biological Systems, Signaling and Communication in Plants, 12. New York: Springer, 283 pp.

Leinhos, G. M. E. \& Buchenauer, H. (1992). Inhibition of rust diseases of cereals by metabolic products of Verticillium chlamydosporium. Journal of Phytopathology, 136, 177-193.

Lindon, J. C., Nicholson, J. K. \& Holmes, E. (2007). The Handbook of Metabonomics and Metabolomics. El sevier B.V., Amsterdam, The Netherlans.

Macia-Vicente, J. G., Rosso, L. C., Ciancio, A., Jansson, H. B. \& Lopez-Llorca, L. V. (2009). Colonization of barley roots by endophytic Fusarium equiseti and Pochonia chlamydosporia: Effects on plant growth and disease. Annals of Applied Biology 155, 391-401.

Manzanilla-López, R.H., Esteves, I., Finetti-Sialer, M., Hirsch, P.R., Ward, E., Devonshire, J. and Hidalgo, L. (2013). Pochonia chlamydosporia: Advances and challenges to improve its performance as a biological control agent of sedentary endo-parasitic nematodes. Journal of Nematology 45, 1-7

Marhuenda-Egea, F. C., Martínez-Sabater, E., Jordá, J., Moral, R., Bustamante, M. A., Paredes C. \& Pérez-Murcia, M. D. (2007). Dissolved organic matter fractions formed during composting of winery and distillery residues: Evaluation of the process by fluorescence excitation-emission matrix. Chemosphere 68(2), 301-309. 
Marhuenda-Egea, F., Gonsavez-Alvarez, R., Lledo-Bosch, B., Ten, J. \& Bernabeu, R. (2013). New Approach for Chemometric Analysis of Mass Spectrometry Data. Analytical Chemistry 85 (6), 3053-3058.

McClURE, M. A., KRUK, T. H. \& MISAGHI, I. (1973). A method for obtaining quantities of clean Meloidogyne eggs. J. Nematol., 5, 230.

Mitchum, M. G., Hussey, R. S., Baum, T. J., Wang, X., Elling, A. A., Wubben, M. \& Davis, E. L. (2013). Nematode effector proteins: an emerging paradigm of parasitism. New Phytologist. 199 (4), 879-894

Mobed, J. J., Hemmingsen, S. L., Autry, J. L. \& McGown, L. B. (1996). Fluorescence characterization of IHSS humic substances: total luminescence spectra with absorbance correction. Environmental Science and Technology 30(10), 3061-3065

Moco, S., Bino, R. J., Vorst, O., Verhoeven, H. A., de Groot, J., van Beek, T. A., Vervoort, J. \& De Vos, R. C. H. (2006). A liquid chromatography-mass spectrometry-based metabolome database for tomato. Plant Physiology 141, 1205-1218

Moco, S., Jenny, F., Vos, R. C. H., Bino, R. J. \& Vervoort, J. (2008). Intra- and inter-metabolite correlation spectroscopy of tomato metabolomics data obtained by liquid chromatography-mass spectrometry and nuclear magnetic resonance. Metabolomics 4 (3), 202-215.

Monfort, E., Lopez-Llorca, L. V., Jansson, H. B., Salinas, J., Park, J. O. \& Sivasithamparam, K. (2005). Colonisation of seminal roots of wheat and barley by egg-parasitic nematophagous fungi and their effects on Gaeumannomyces graminis var. tritici and development of root-rot. Soil Biology and Biochemistry 37, 1229-1235.

Ohno, T. \& Bro, R. (2006). Dissolved organic matter characterization using multiway spectral decomposition of fluorescence landscapes. Soil Sci. Soc. Am. J. 70(6), 2028-2037.

Olivares-Bernabeu, C. M., \& López-Llorca, L. V. (2002). Fungal egg-parasites of plant-parasitic nematodes from spanish soils. Revista Iberoamericana De Micologia, 19(2), 104-110.

Patti, G. J., Tautenhahn, R. \& Siuzdak, G. (2012). Meta-analysis of untargeted metabolomic data from multiple profiling experiments. Nature Protocols 7(3), 508-516. 
Parlanti, E., Wörz, K., Geoffroy, L. \& Lamotte, M. (2000). Dissolved organic matter fluorescence spectroscopy as a tool to estimate biological activity in a coastal zone submitted to anthropogenic inputs. Org. Geochem. 31(12), 1765-1781.

Provenzano, M. R., de Oliveira, S. C., Santiago Silva \& M. R., Senesi, N. (2001). Assessment of maturity degree of composts from domestic solid wastes by fluorescence and Fourier transform infrared spectroscopies. J. Agric. Food. Chem. 49(12), 5874-5879.

Rao, M. S., P. P. Reddy, A. Mittal, M. V. Chandravadana, and M. Nagesh. 1996. Effect of some secondary plant metabolites as seed treatment agents against Meloidogyne incognita on tomato. Nematologia Mediterranea 24, 49-51.

Rovira, A. D., Newman, E. I., Bowen, H. J. \& Campbell, R. (1974). Quantitative assessment of the rhizosphere microflora by direct microscopy. Soil Biol. Biochem. 6, 211-16.

Savorani, F., Tomasi, G. \& Engelsen S.B. (2010). icoshift: A versatile tool for the rapid alignment of 1D NMR spectra. Journal of Magnetic Resonance 202, 190-202

Sierra, M. M. D., Giovanela, M., Parlanti, E. \& Soriano-Sierra, E. J. (2005). Fluorescence fingerprint of fulvic and humic acids from varied origins as viewed by single-scan and excitation/emission matrix techniques. Chemosphere 58, 715-733.

Simons, M., Permentier, H. P., de Weger, L. A., Wijffelman, C. A. \& Lugtenberg, B. J. J. (1997). Amino acid synthesis is necessary for tomato root colonization by Pseudomonas fluorescens strain WCS365. MPMI 10 (1), 102-106.

Tanda, A. S., Atwal, A. S. \& Bajaj, P. S. (1985). In vitro inhibition of root-knot nematode Meloidogyne incognita by sesame root exudate and its amino acids. Nematologica 35, 115-124.

Teillet, A., Dybal, K., Kerry, B., Miller, A., Curtis, R. \& Hedden, P. (2013). Transcriptional Changes of the Root-Knot Nematode Meloidogyne incognita in Response to Arabidopsis thaliana Root Signals. PLoS ONE 8(4), e61259

Teixeira-Machado, A. R., Costa-Campos, V. A, Rodrigues-Silva, W. J., Campos, V. P. de Mattos-Zeri, A. C. \& Ferreira-Oliveira, D. (2012). Metabolic profiling in the roots of coffee plants exposed 
to the coffee root-knot nematode, Meloidogyne exigua. European Journal of Plant Pathology 134(2), 431-441.

Tzortzakakis, E. A. (2007). The effect of the fungus Pochonia chlamydosporia on the root-knot nematode Meloidogyne incognita in pots. Russian Journal of Nematology, 15(2), 89-94.

Van Grundy, S.D., Kirkpatrick, J. D. and Golden, J. (1977). The nature and role of metabolic leakage from root-Knot nematode galls and infection by Rhizoctonia solani. Journal of Nematology 113-121.

Verboven, S. \& Hubert, M. (2005). LIBRA: a MATLAB Library for Robust Analysis. Chemom. Intell. Lab. Syst. 75(2), 127-136.

Viant, M.R. \& Sommer, U. (2013). Mass spectrometry based environmental metabolomics: a primer and review. Metabolomics 9, S144-S158.

Vivanco, J. M., Guimaraes R. L. \& Flores, E. (2002). Underground Plant Metabolism: The biosynthetic Potential of Roots". In "Plant roots: The hidden half. Thirth edition. Edited by Waisel, Y., Eshel, A., Kafkafi.

Vos, C., Claerhout, S., Mkandawire, R., Panis, B., Waele, D., \& Elsen A., (2012). Arbuscular mycorrhizal fungi reduce root-knot nematode penetration through altered root exudation of their host. Plant and soil 354 (1-2), 335-345.

Wuyts, N., Swennen, R. \& De Waele, D. (2006). Effects of plant phenylpropanoid pathway products and selected terpenoids and alkaloids on the behaviour of the plant-parasitic nematodes Radopholus similis, Pratylenchus penetrans and Meloidogyne incognita. Nematology 8, 89-101.

Zhang, H-J., Wei, Z-G., Zhao, H-Y, Yang, H-X. \& Hu F. (2009). Effects of Low-Molecular-Weight Organic Acids on Gadolinium Accumulation and Transportation in Tomato Plants. Biol Trace Elem Res 127 (1), 81-93

Zhao, B. G. (1999). Nematicidal activity of quinolizidine alkaloids and the functional group pairs in their molecular structure. Journal of Chemical Ecology 25, 2205-2214. 


\section{Figure Legends}

Figure 1. Contour Excitation-emission matrix (EEM) spectra of tomato root exudates at the $58 / 6$ 9 507

Figure 5. ROBPCA score and loading plots from the analysis of HPLC-MS data of early tomato root exudates (17 days after planting, 7 dai). Loadings from PC1 corresponding to score plots are inserted in the figures. (a) Positive mode in low molecular weight range. (b) Positive mode in medium/high molecular weight range. (d) Negative mode in low molecular weight range. (e) Negative mode in

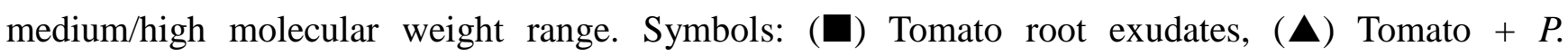
chlamydosporia,$(\square)$ Tomato + M. javanica,$(\triangle)$ Tomato $+P$. chlamydosporia + M. javanica . 
Figure 6. ROBPCA score and loading plots from analysis of HPLC-MS data of late tomato root exudates (50 days after planting, 43 dai). Loadings from PC1 corresponding to score plots are inserted in the figures. (a) Positive mode in low molecular weight range. (a) Positive mode in low molecular weight range. (b) Positive mode in medium/high molecular weight range. (d) Negative mode in low molecular weight range. (e) Negative mode in medium/high molecular weight range. Symbols:

Tomato root exudates, $(\mathbf{\Delta})$ Tomato $+P$. chlamydosporia, $(\square)$ Tomato $+M$. javanica,$(\triangle)$ Tomato $+P$. chlamydosporia + M. javanica.

Figure 7. Venn Diagrams classification of the m/z signals from HPLC-MS from early (a-c) and late (de) tomato root exudates with significant differences in intensity respect to those of tomato uninoculated plants. a) Total $\mathrm{m} / \mathrm{z}$ signals that exhibit statistically significant respect to uninoculated tomato plants. b) $\mathrm{M} / \mathrm{z}$ signals with lower intensity respect to uninoculated tomato plants. c) $\mathrm{M} / \mathrm{z}$ signals with higher intensity respect to uninoculated tomato plants. d) Total $\mathrm{m} / \mathrm{z}$ signals that exhibit statistically significant differences respect to uninoculated tomato plants. e) $M / z$ signals with lower intensity respect to uninoculated tomato plants. f) $\mathrm{M} / \mathrm{z}$ signals with higher intensity respect to uninoculated tomato plants.

Table 1. Peak assignments for ${ }^{1} \mathrm{H}$ NMR spectrum of tomato root exudates. Compounds are separated in the three regions of the spectrum: (I) amino acids-organic acids, (II) sugars-polyalcohols and (III) aromatic compounds. Abbreviations: s (singlet), d (doublet), m (multiplet), nd (not determined).

\section{Online resources}

OR 1. Fluorescence data of tomato root exudates representing Principal component 1 (PC1) respect to PC 2. Solid circles represent data from early (17 days after planting, 7 day) root exudates invasion moment and solid triangles represent data from late (50 days after planting, 43 dai) root exudates, day (days after inoculation with $M$. javanica).

OR 2. Box plots analyses of the fluorescence spectra data of principal components of tomato root. a) PC 1 of early root exudates. b) PC 2 of early root exudates. c) PC 1 of late root exudates. d) PC 1 of late roots exudates. Sample size $=10$. Different letters above bars indicate significant differences $(p-$ value <0.05). Treatment abbreviation: To (Tomato), Pc (Tomato inoculated with P. chlamydosporia), To+RKN (Tomato inoculated with $M$. javanica) and To+Pc+ RKN (Tomato inoculated with $P$. chlamydosporia and $M$. javanica), day (days after inoculation with $M$. javanica). 
OR 3. HPLC-MS profiles measured in positive mode in low molecular weight range of early tomato 636 root exudates (17 days after planting, 7 day). a) To. b) To+Pc c) To+RKN d) To+Pc+RKN. And late 637 Abbreviations: To: Tomato, Pc: P. chlamydosporia, RKN: Root-knot nematodes (M. javanica), day (days after inoculation with $M$. javanica).

OR 4. HPLC-MS profiles measured in positive mode in medium-high molecular weight range of early tomato root exudates (17 days after planting, 7 day). a) To. b) To+Pc c) To+RKN d) To+Pc+RKN. And late root exudates (50 days after planting, 43 dai) e) To. f) To+Pc g) To+RKN h) To+Pc+RKN. Abbreviations: To: Tomato, Pc: P. chlamydosporia, RKN: Root-knot nematodes (M. javanica), day (days after inoculation with $M$. javanica).

OR 5. HPLC-MS profiles measured in negative mode in low molecular weight range of early tomato root exudates (17 days after planting, 7 dai) a) To. b) To+Pc c) To+RKN d) To+Pc+RKN. And late root exudates (50 days after planting, 43 dai) e) To. f) To+Pc g) To+RKN h) To+Pc+RKN. Abbreviations: To: Tomato, Pc: P. chlamydosporia, RKN: Root-knot nematodes ( $M$. javanica), dai (days after inoculation with $M$. javanica).

OR 6. HPLC-MS profiles measured in negative mode in low molecular weight range of early tomato root exudates (17 days after planting, 7 dai). a) To. b) To+Pc c) To+RKN d) To+Pc+RKN. And late root exudates (50 days after planting, 43 dai) e) To. f) To+Pc g) To+RKN h) To+Pc+RKN. Abbreviations: To: Tomato, Pc: P. chlamydosporia, RKN: Root-knot nematodes (M. javanica), dai (days after inoculation with $M$. javanica).

Table 2. Integral area of the $\mathrm{m} / \mathrm{z}$ signals selected in the loadings of PC1 from early and late root exudates. The table was classified according to the molecular weight of the $\mathrm{m} / \mathrm{z}$ signals and the ionization mode: positive or negative. The value in bold are the $\mathrm{m} / \mathrm{z}$ signals with significant difference $(\mathrm{p}<0.05)$ from those of uninoculated tomato exudates, and in the final column is indicated the intensity: higher (+) or lower (-). 
Raw

a)

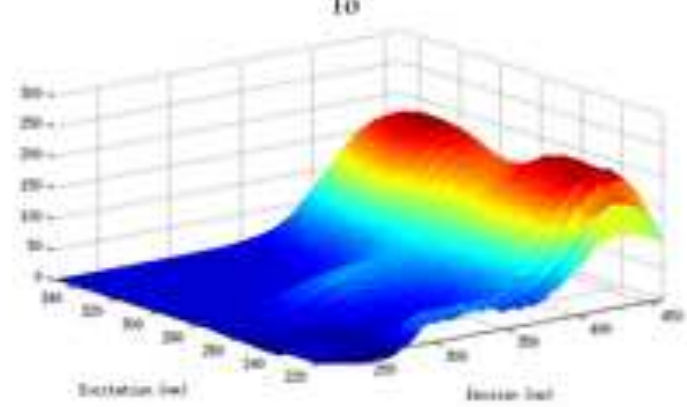

b)

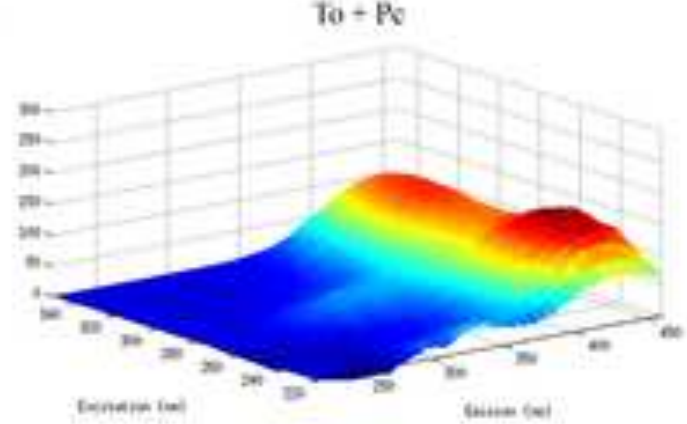

c)

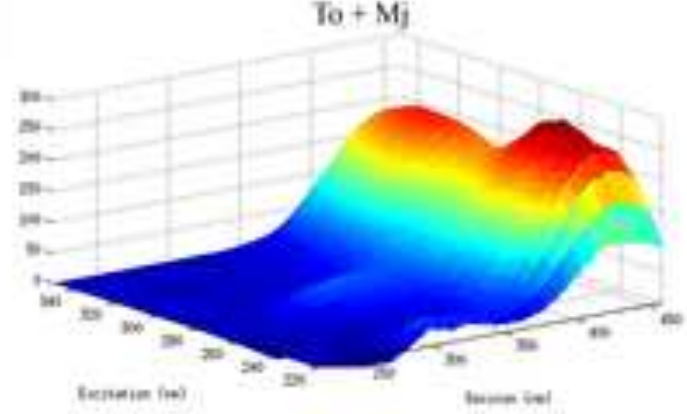

d)

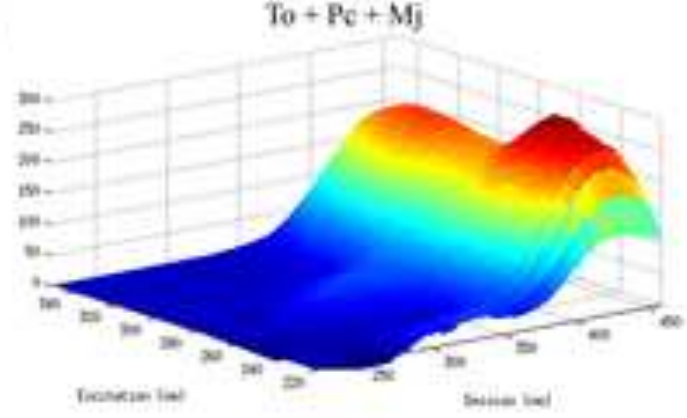

Model

To

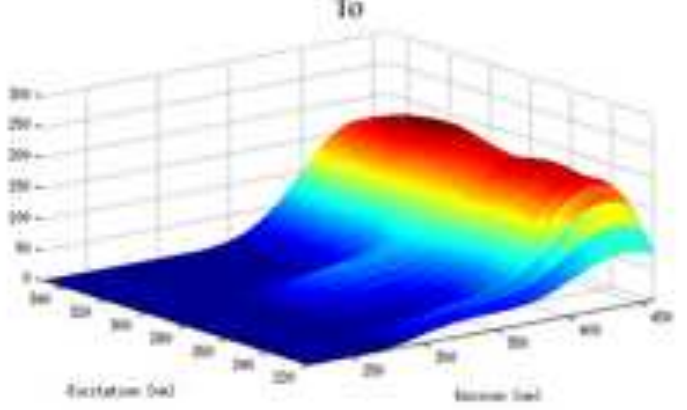

$\mathrm{To}+\mathrm{Pc}$
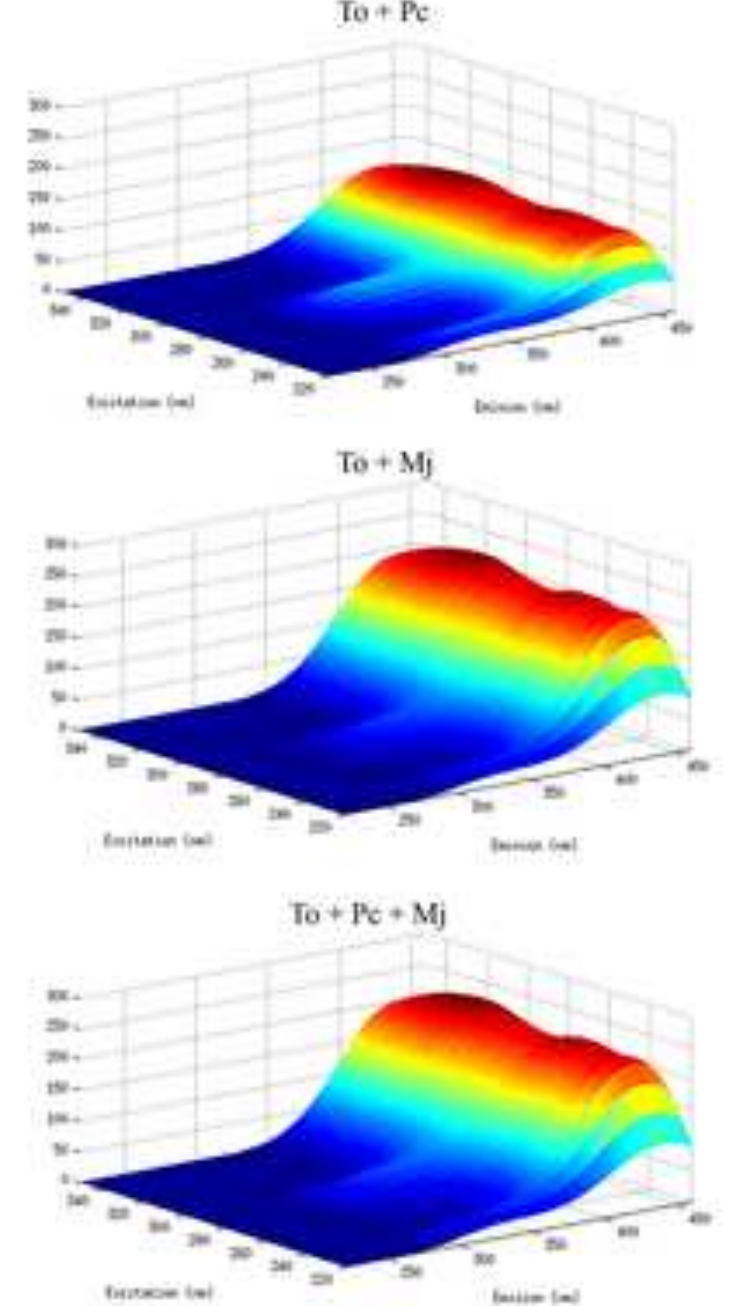

Residual

To

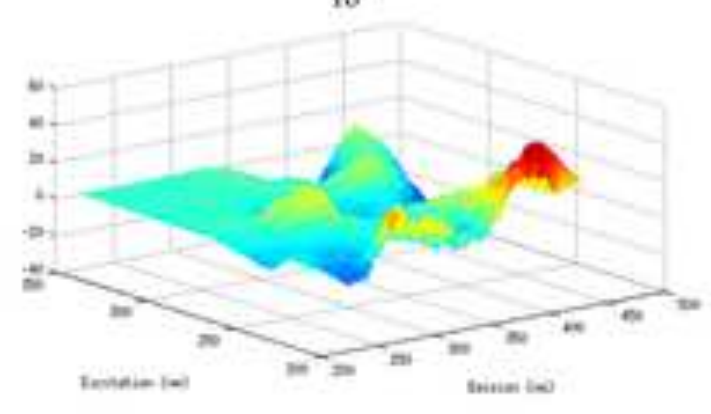

$T_{0}+\mathrm{Pc}_{c}$

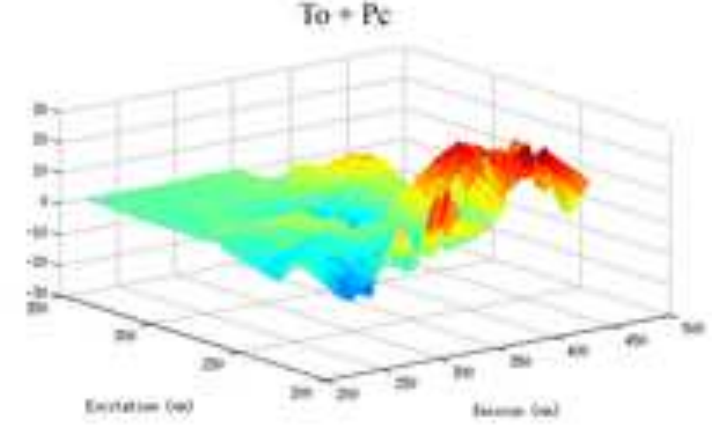

$\mathrm{To}+\mathrm{Mj}$
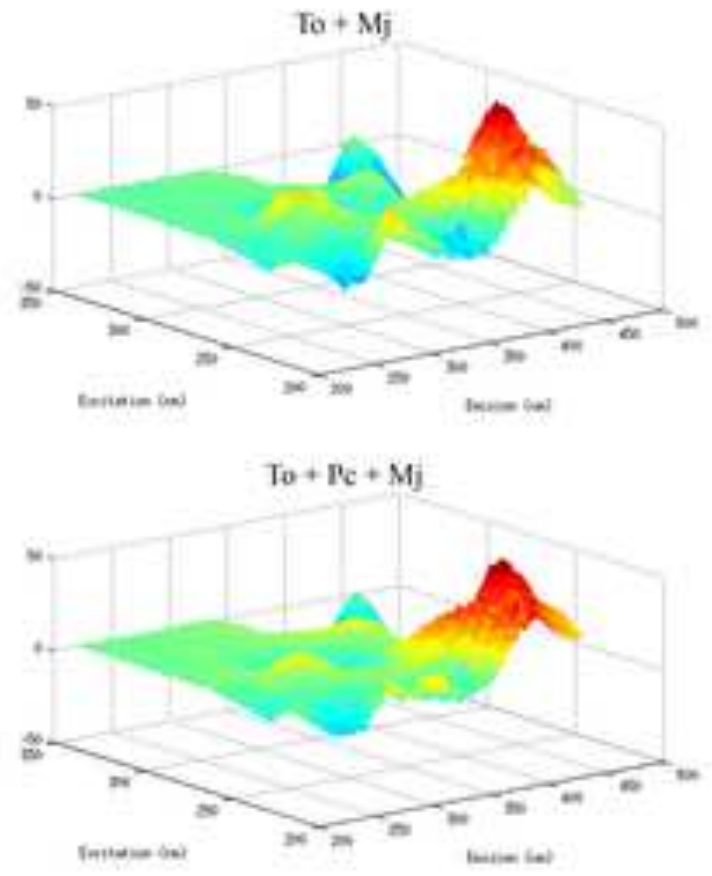
Raw

e)

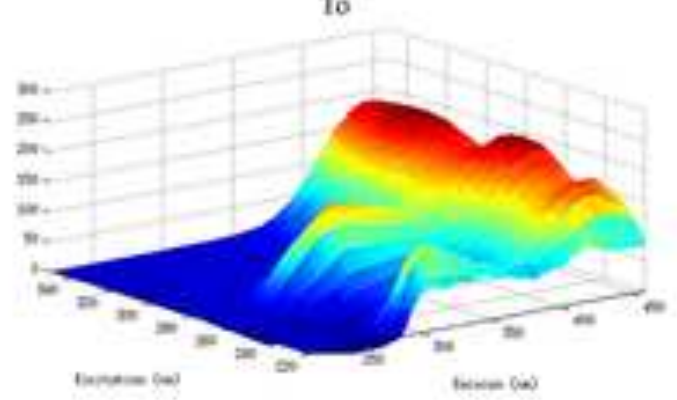

f)

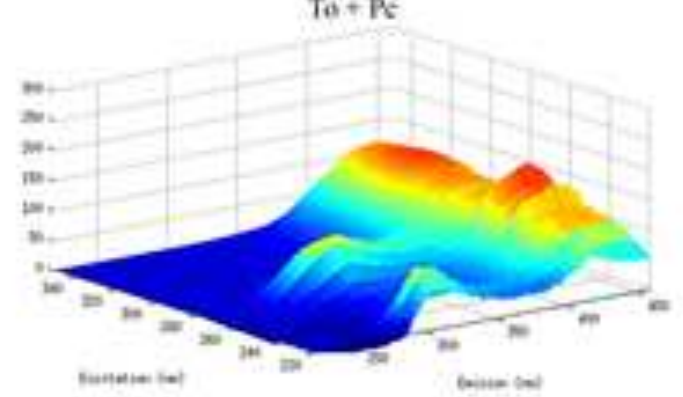

g)

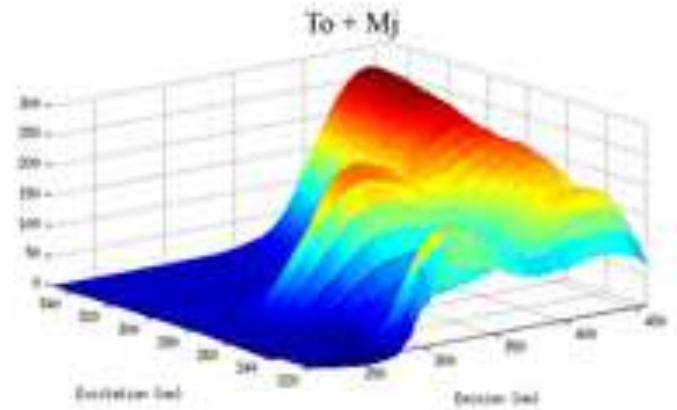

h)

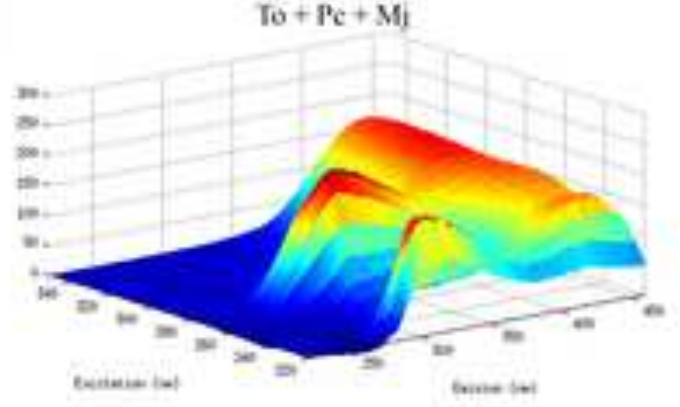

Model

to

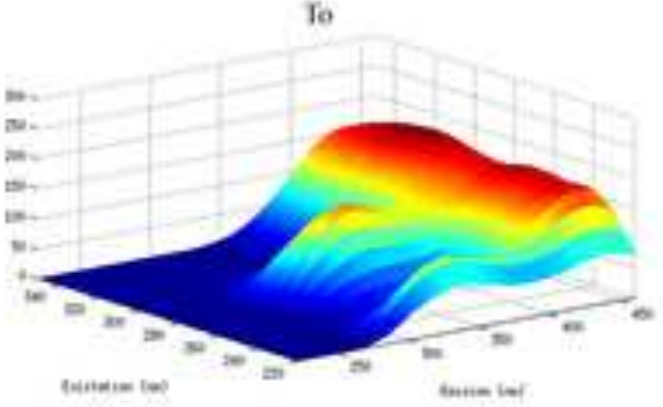

$\mathrm{Ta}+\mathrm{Pe}$
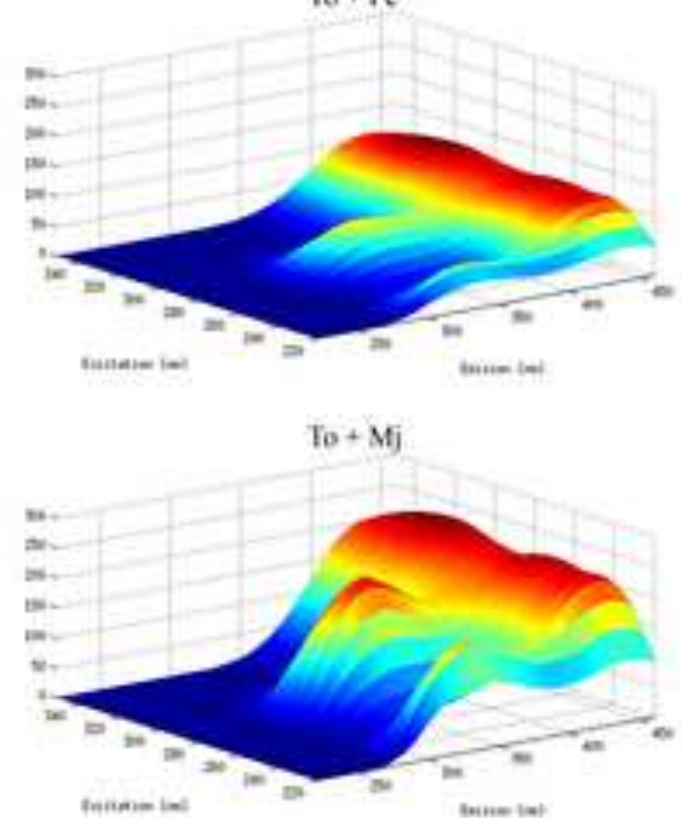

nenom in

$\mathrm{To}+\mathrm{Pc}+\mathrm{Mj}$

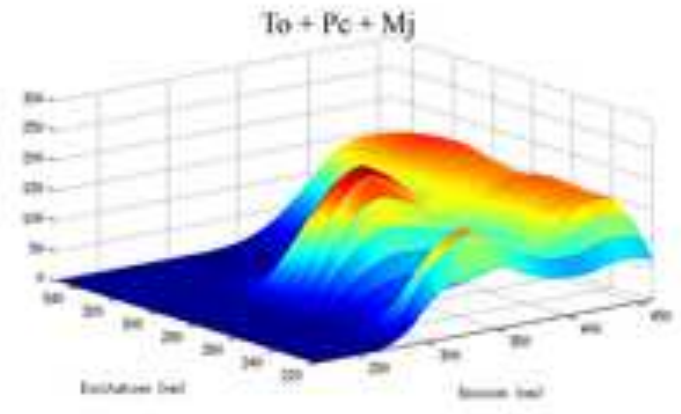

Residual

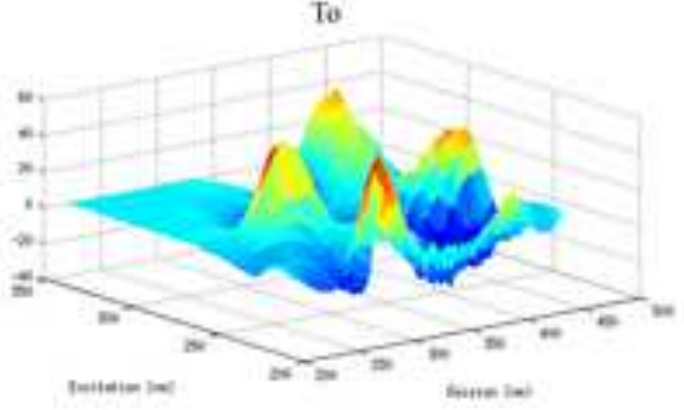

$\mathrm{To}+\mathrm{Pe}$
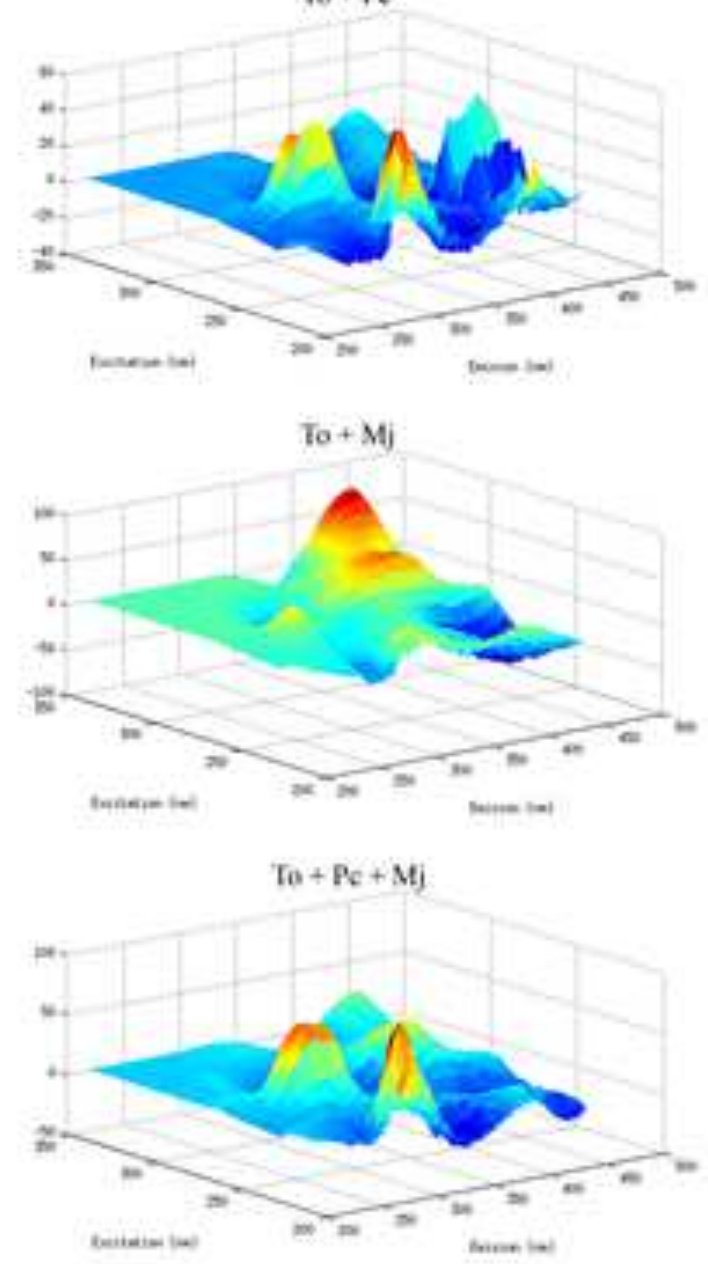
Figure 3

Click here to download high resolution image

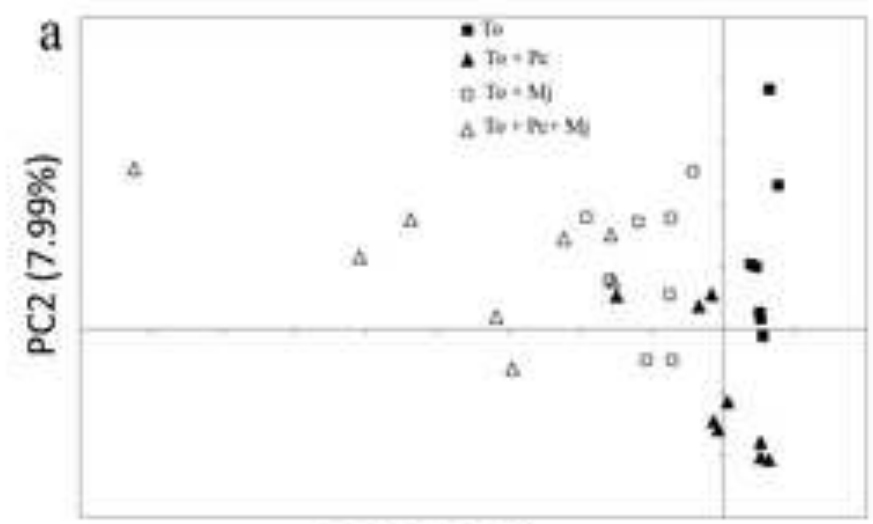

PC1 (73.31\%)

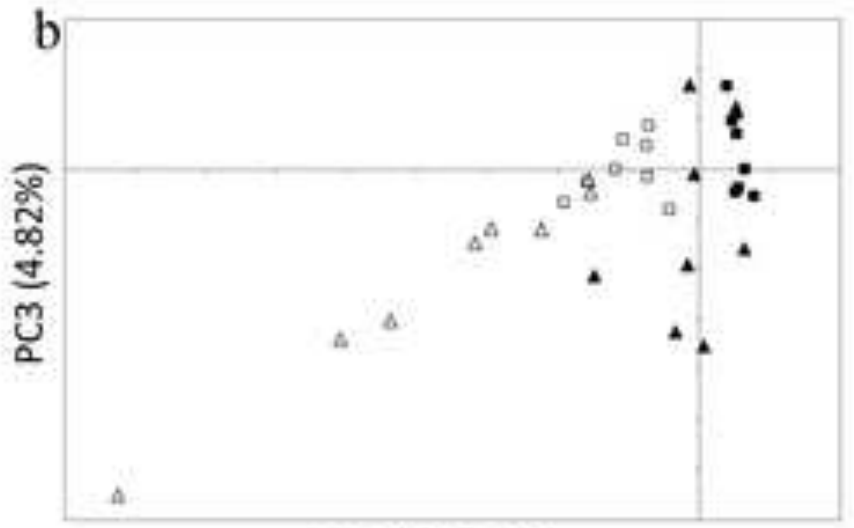

PC1 (73.31\%)

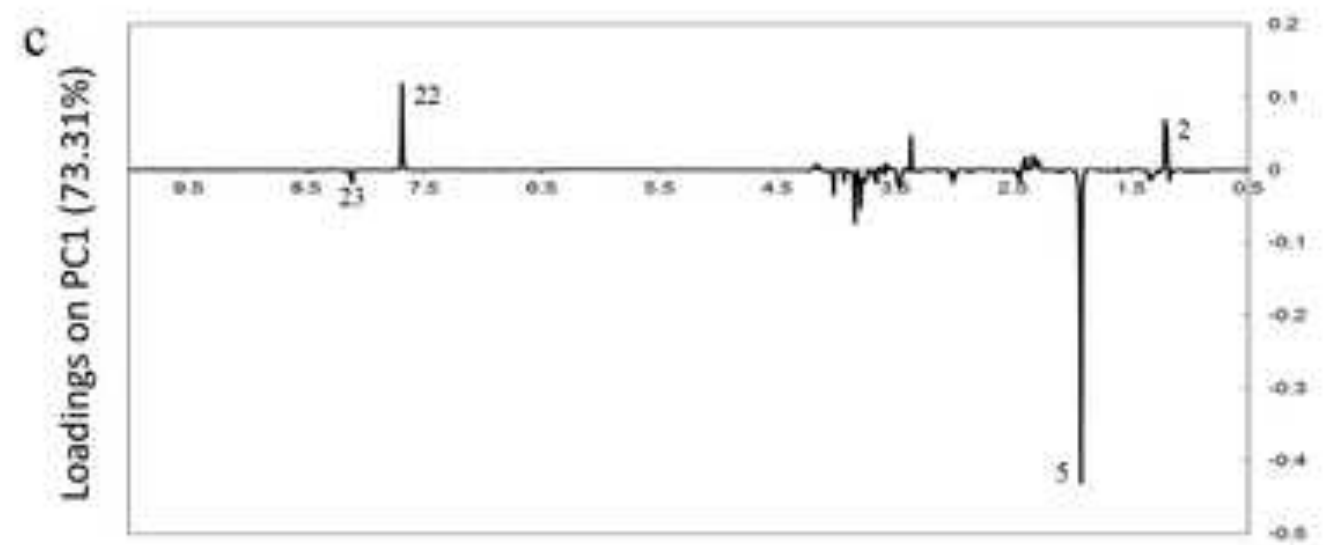

d
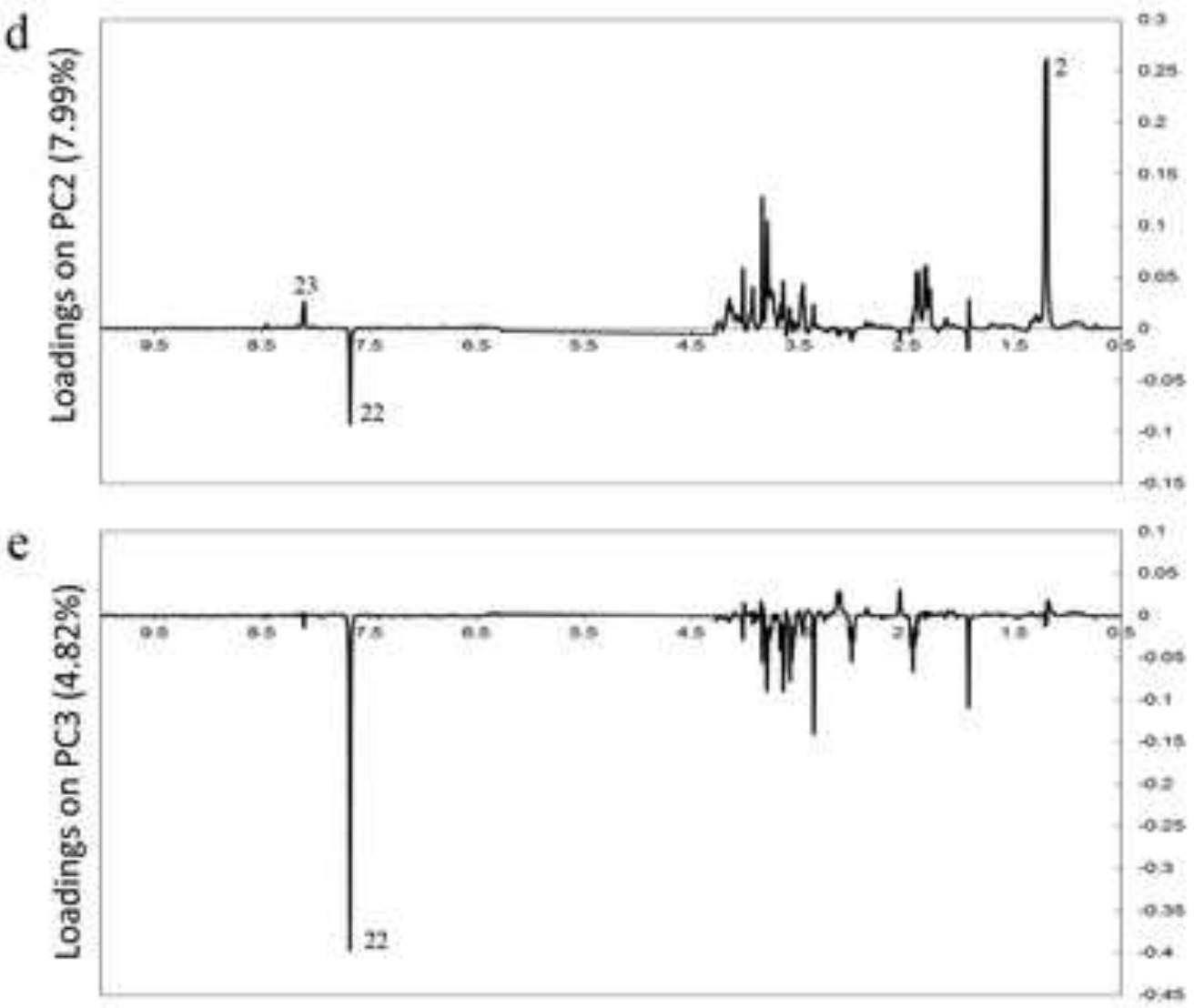

Chemical shift (ppm) 
Figure 4

Click here to download high resolution image

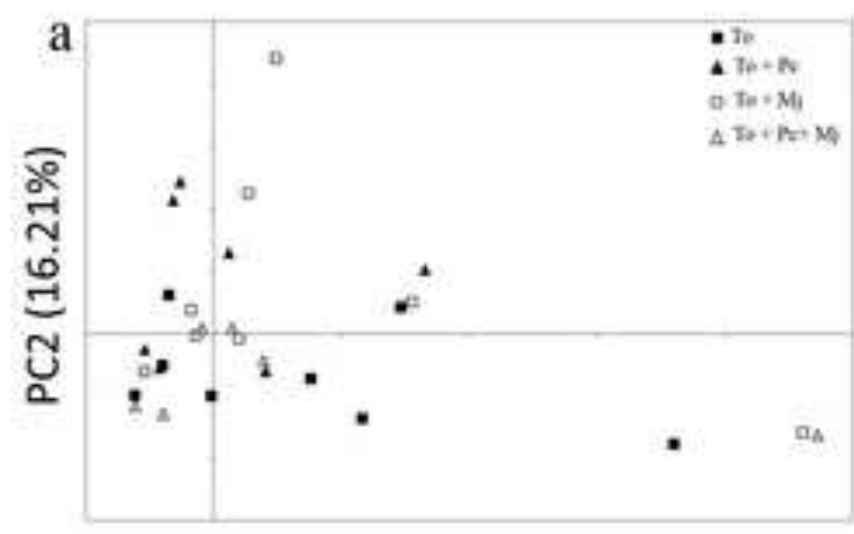

PC1 $(65.92 \%)$

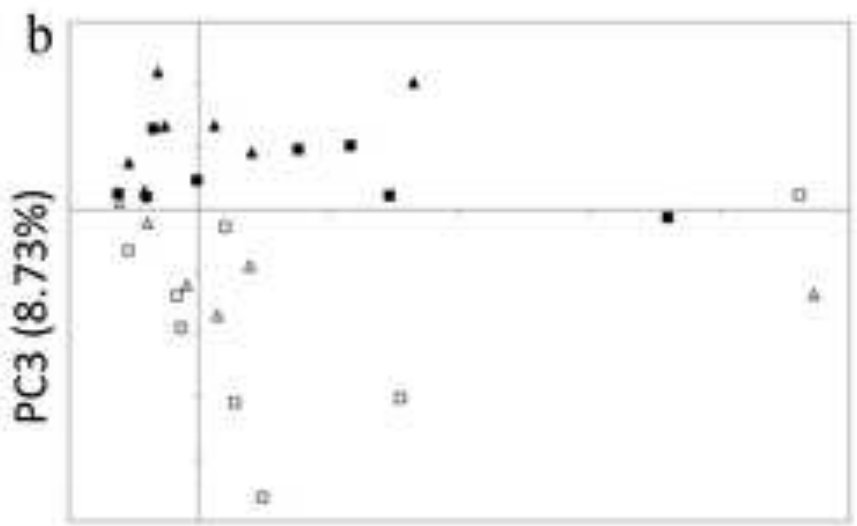

PC1 (65.92\%)

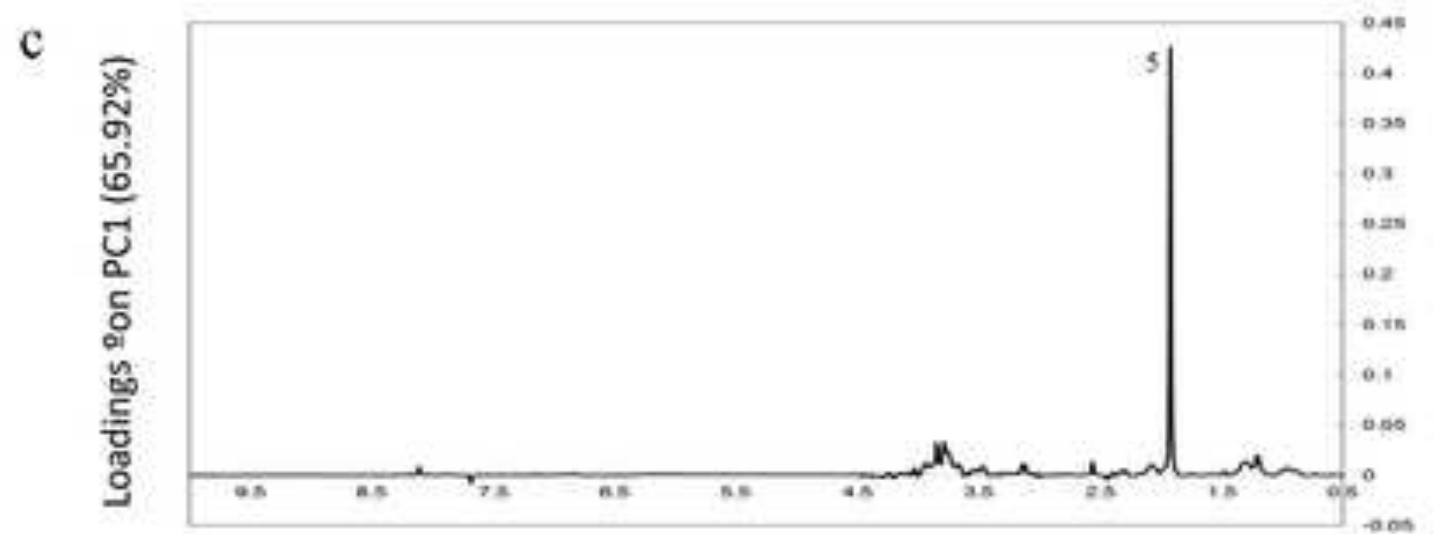

d

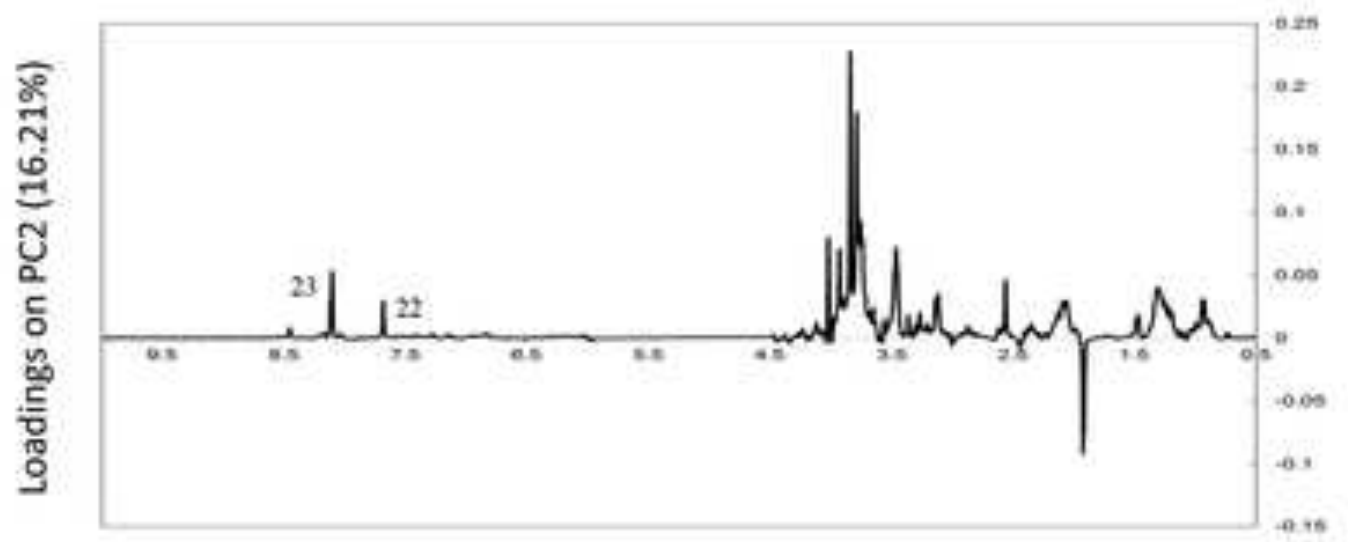

e

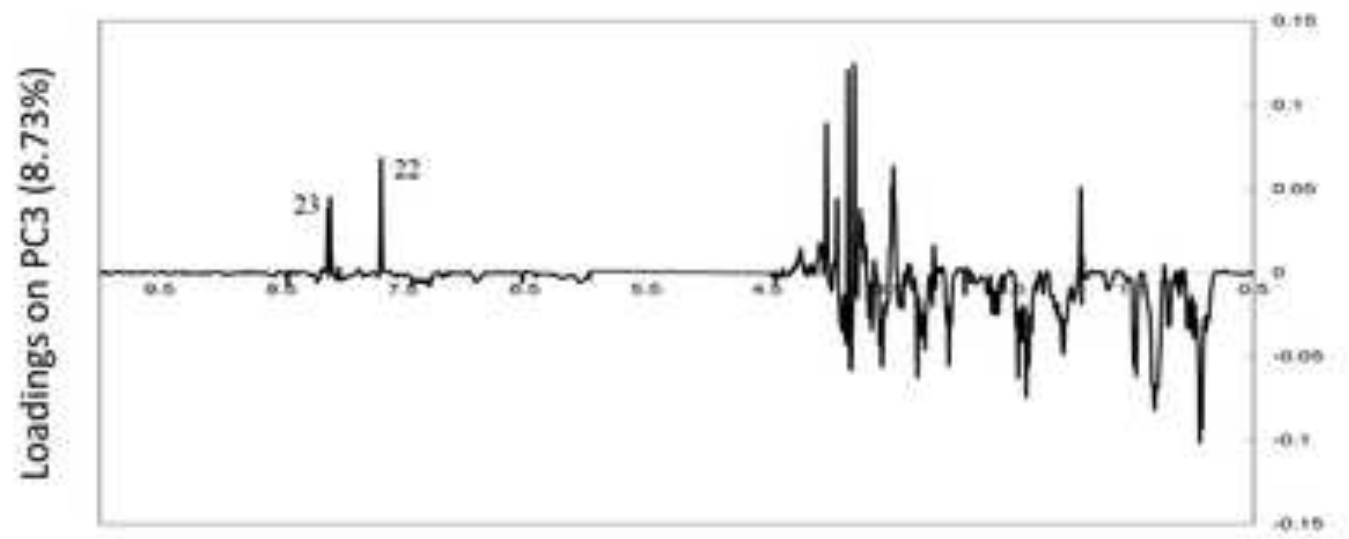

Chemical shift (ppm) 
Figure 5

Click here to download high resolution image

a

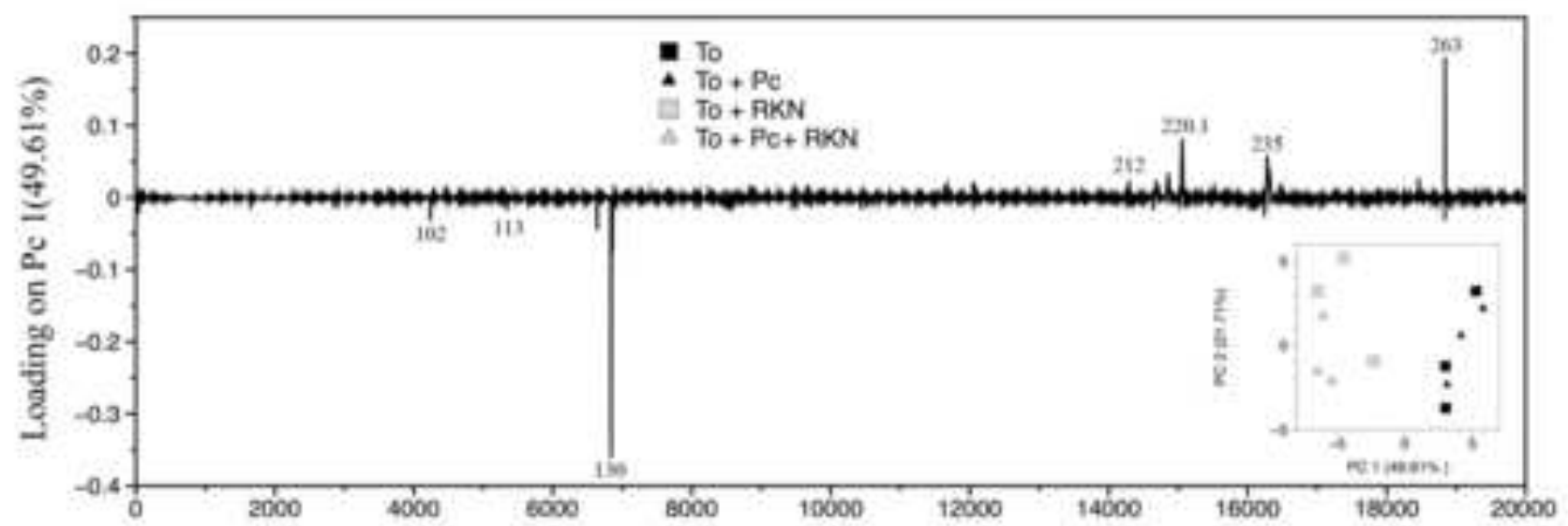

b

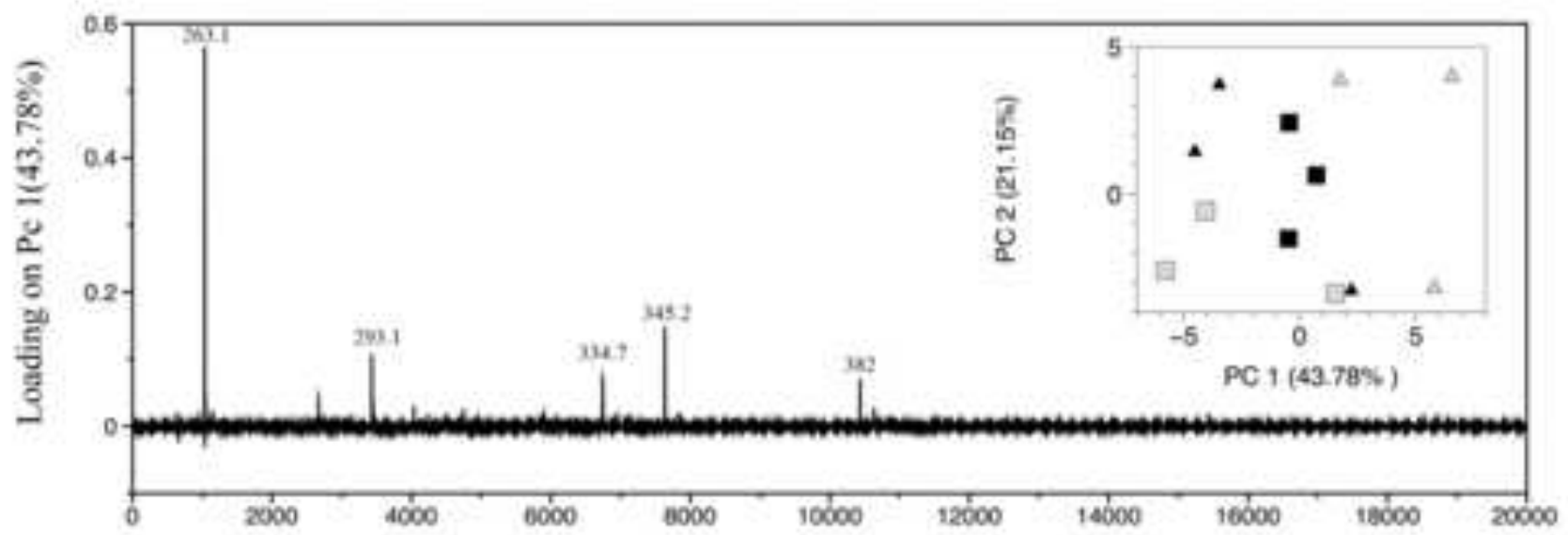

c

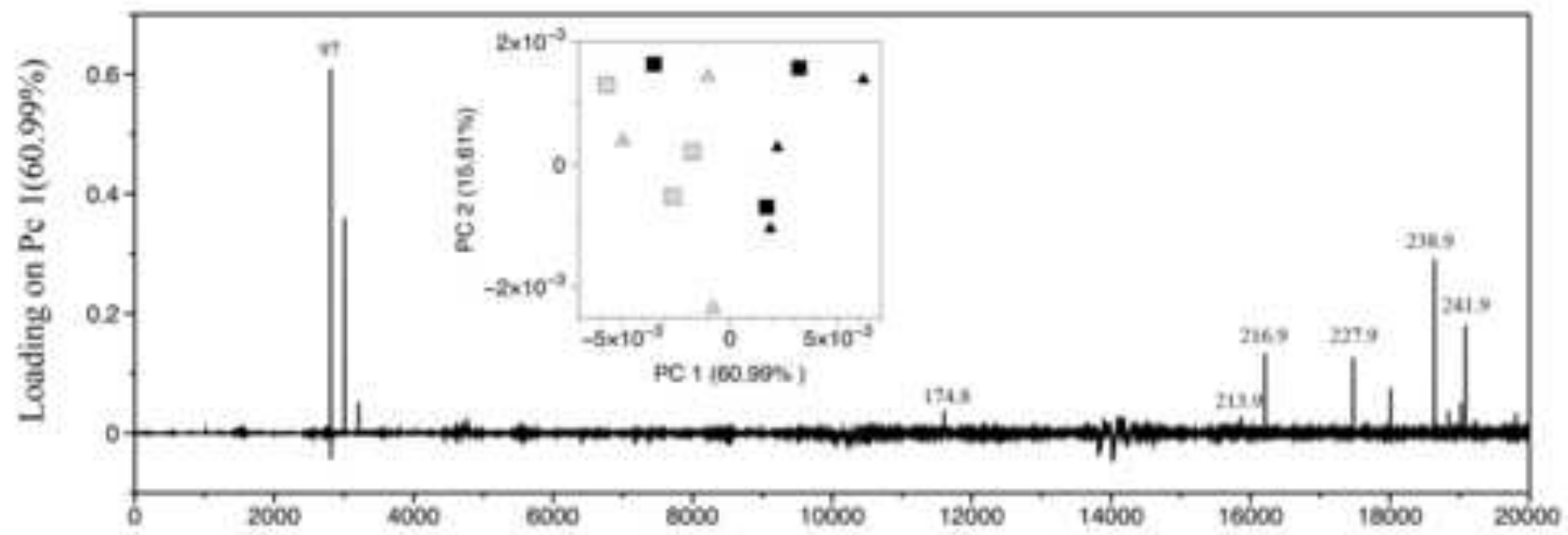

d

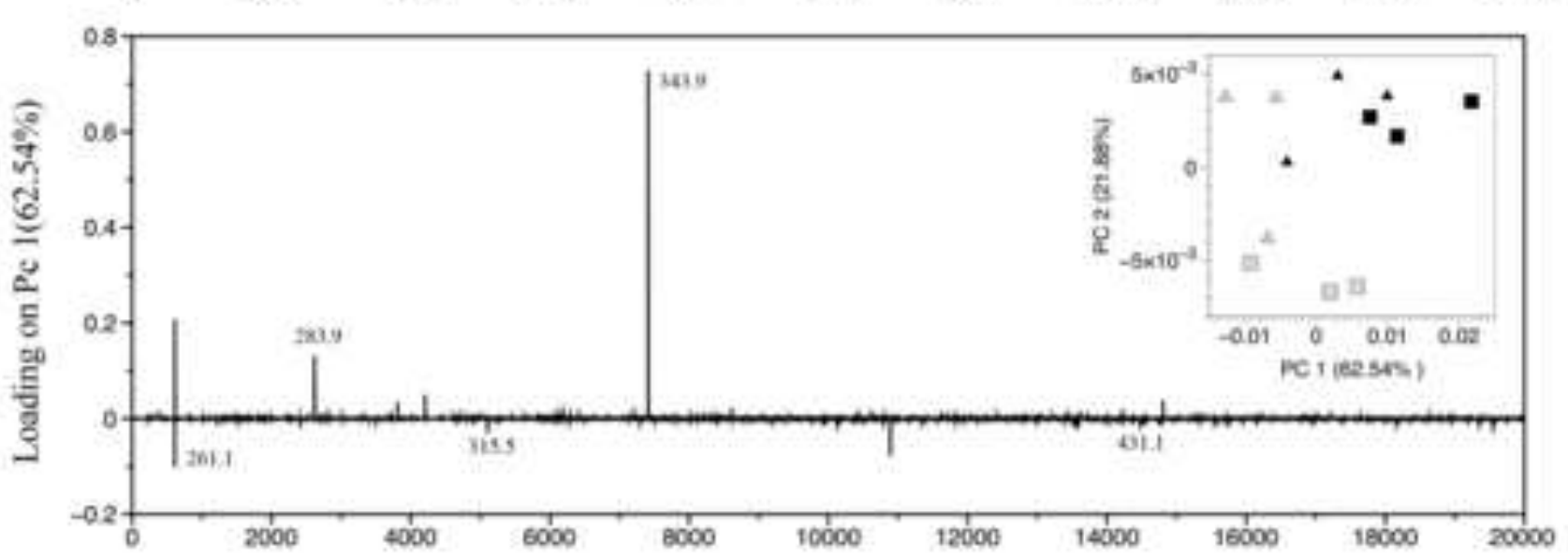


Figure 6

Click here to download high resolution image

a

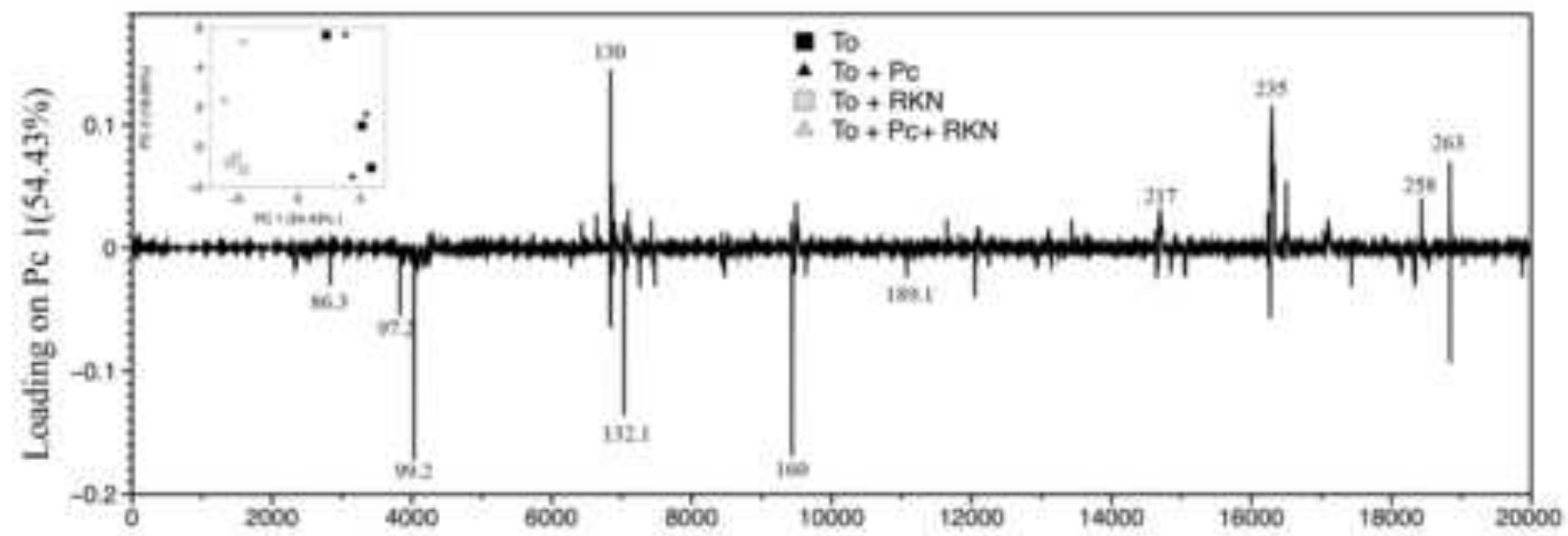

b

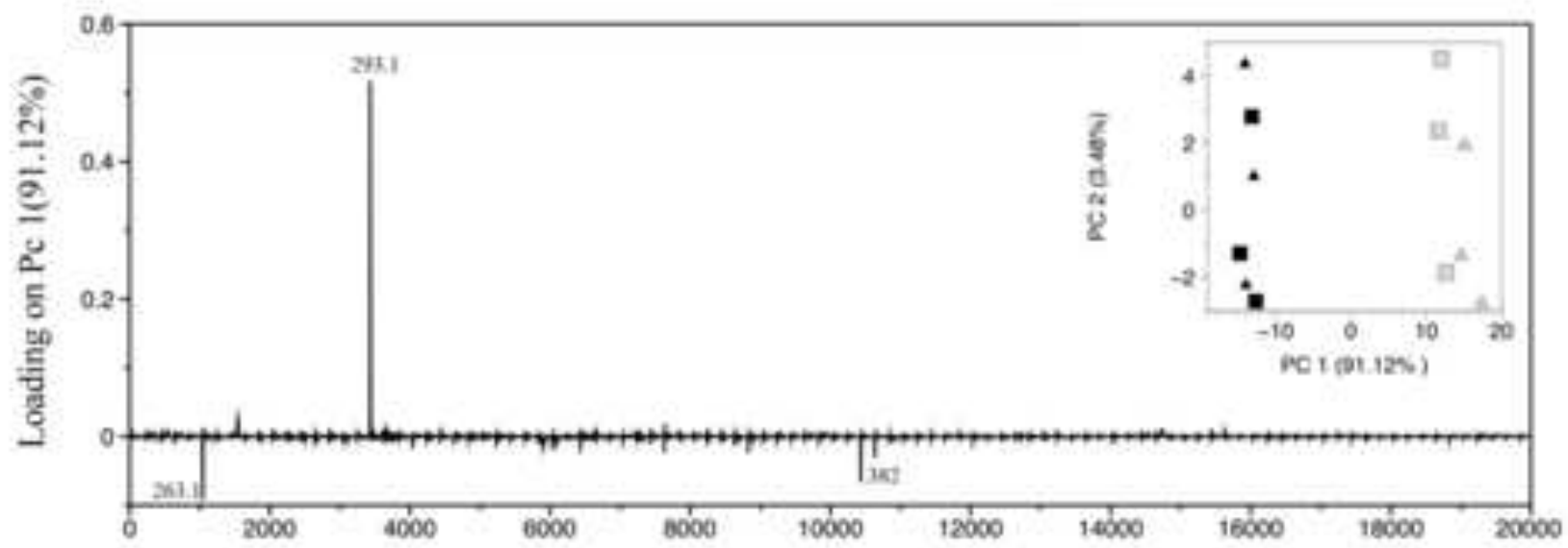

c

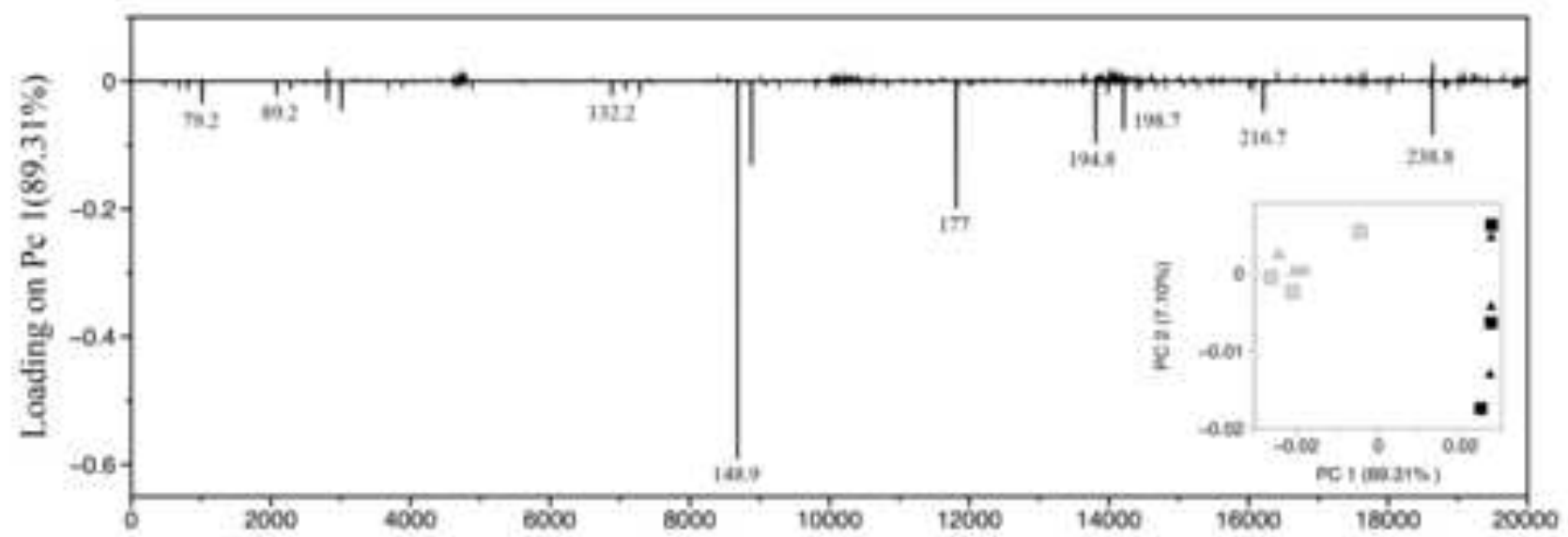

d

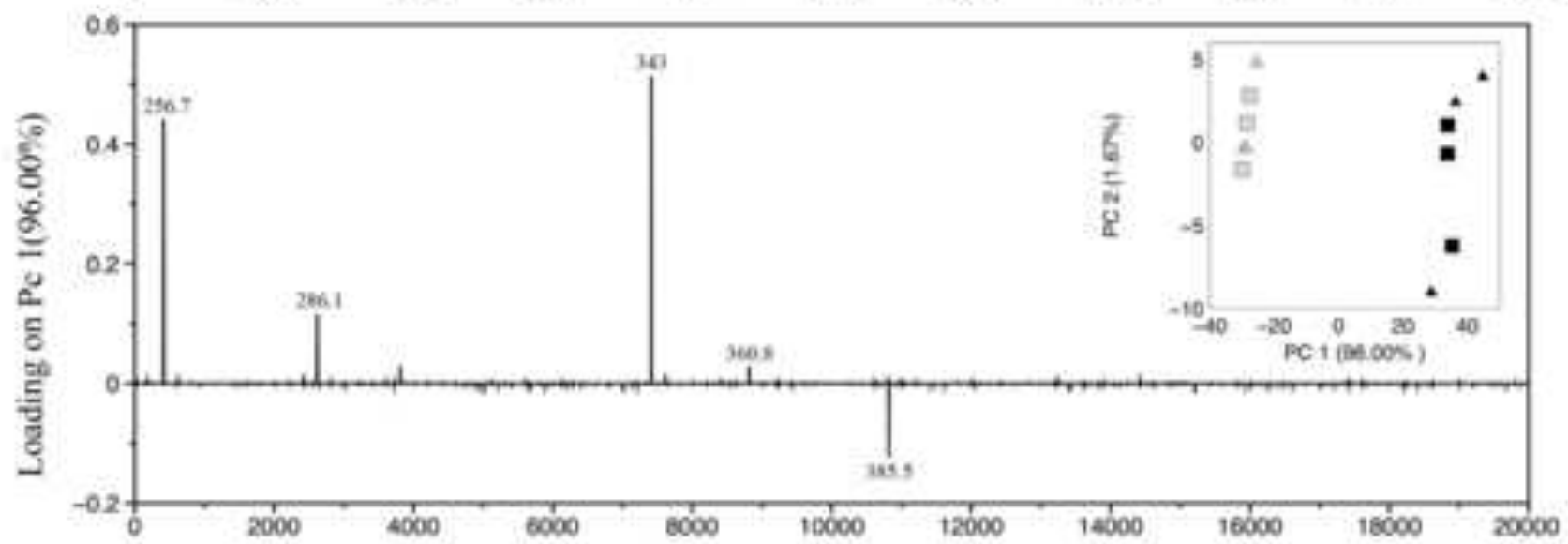


Total
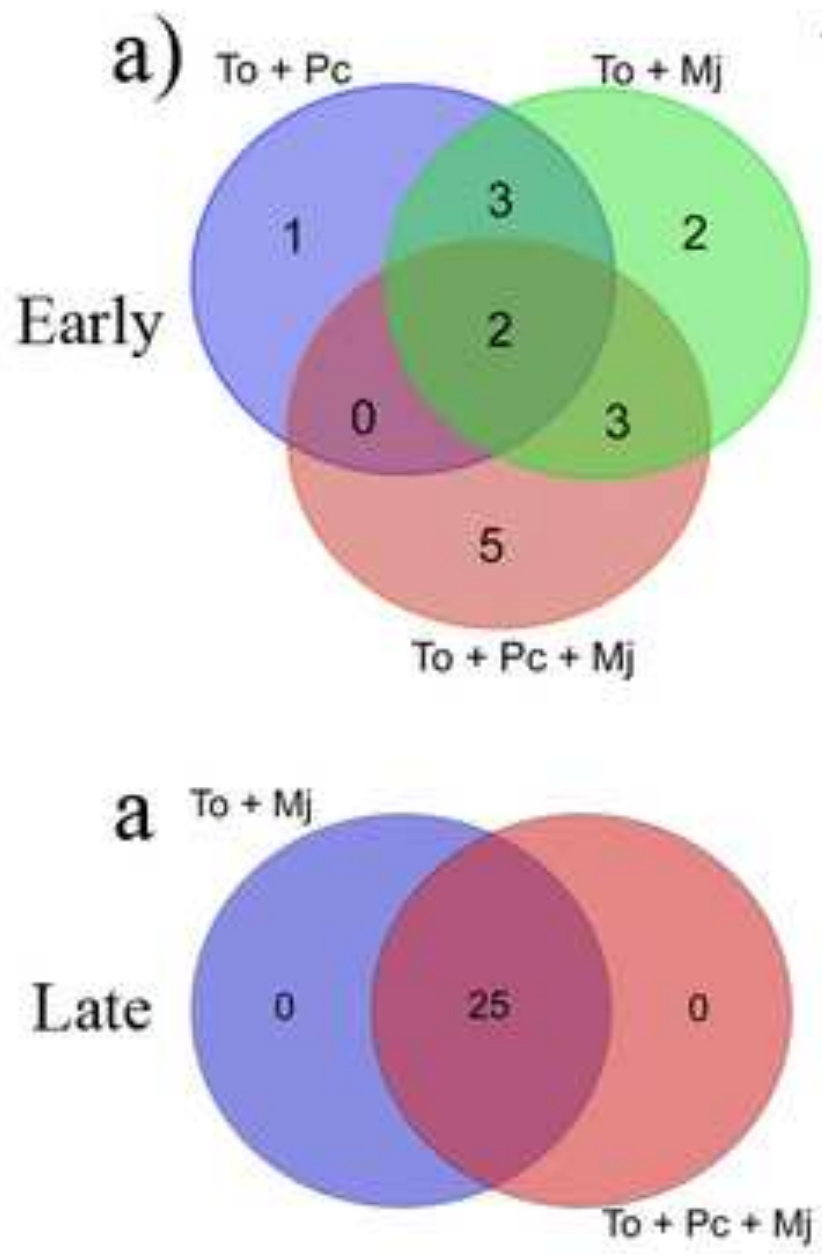

Lower intensity

b)

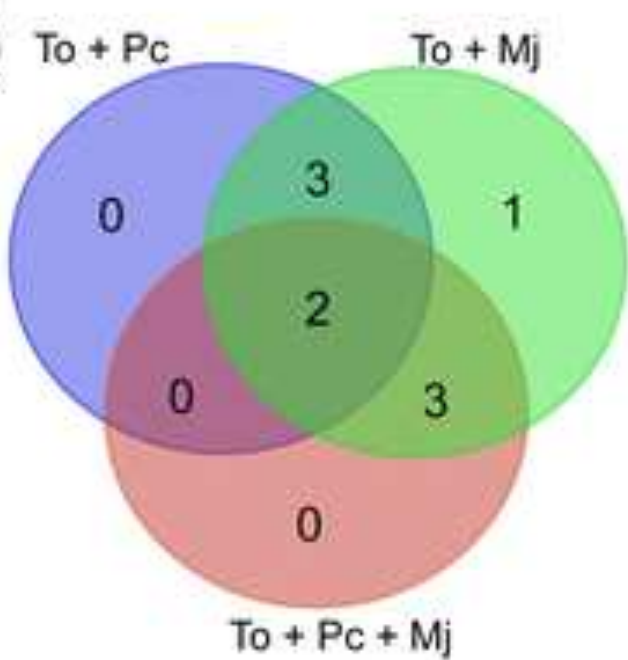

$a^{T o}+M j$

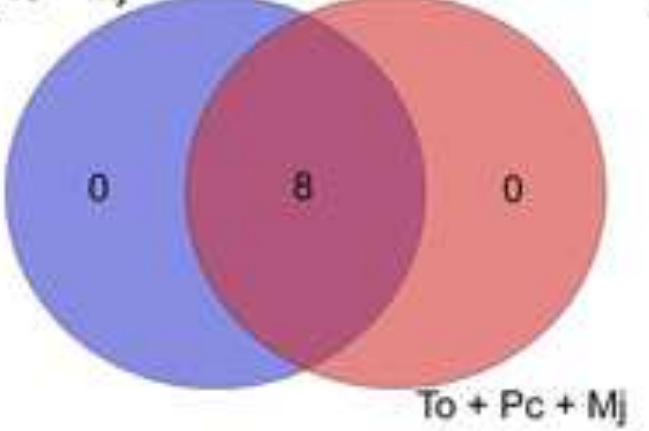

Higher intensity
C) $\mathrm{To}_{\mathrm{O}}+\mathrm{Pc} \quad \mathrm{To}+\mathrm{Mj}$

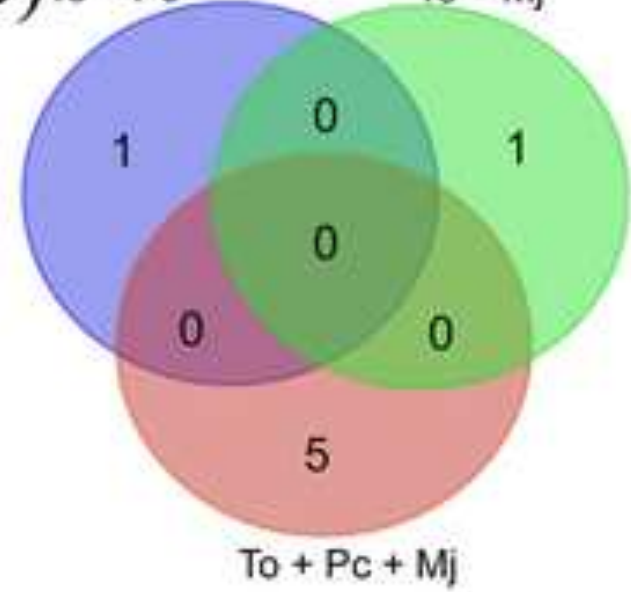

a

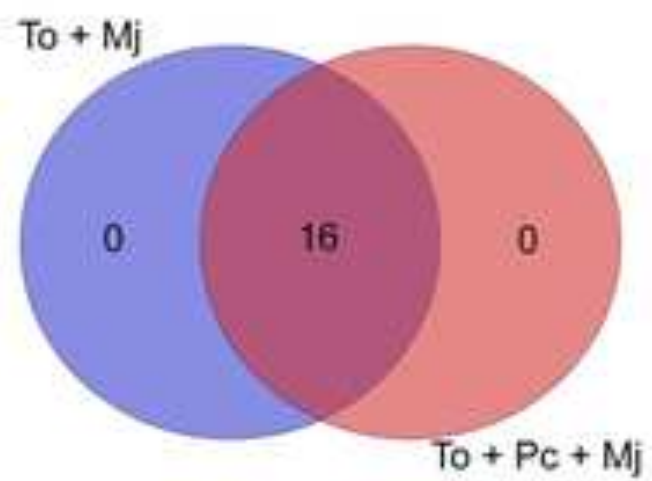


Click here to download high resolution image

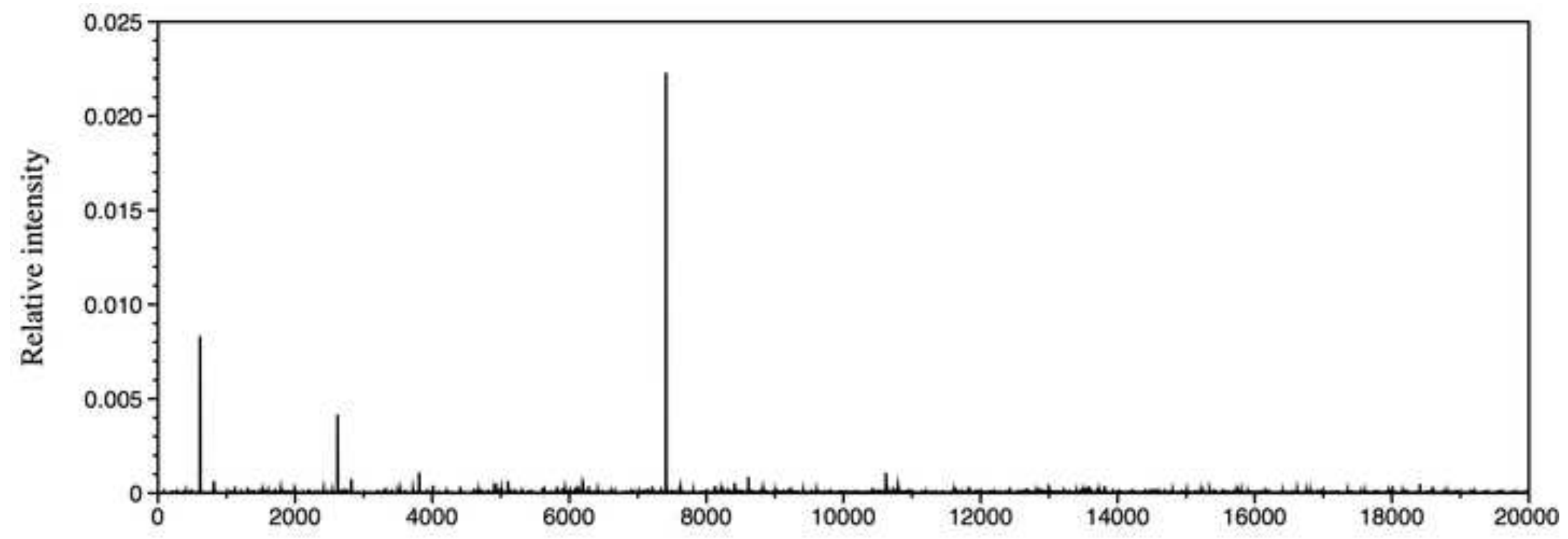


a)

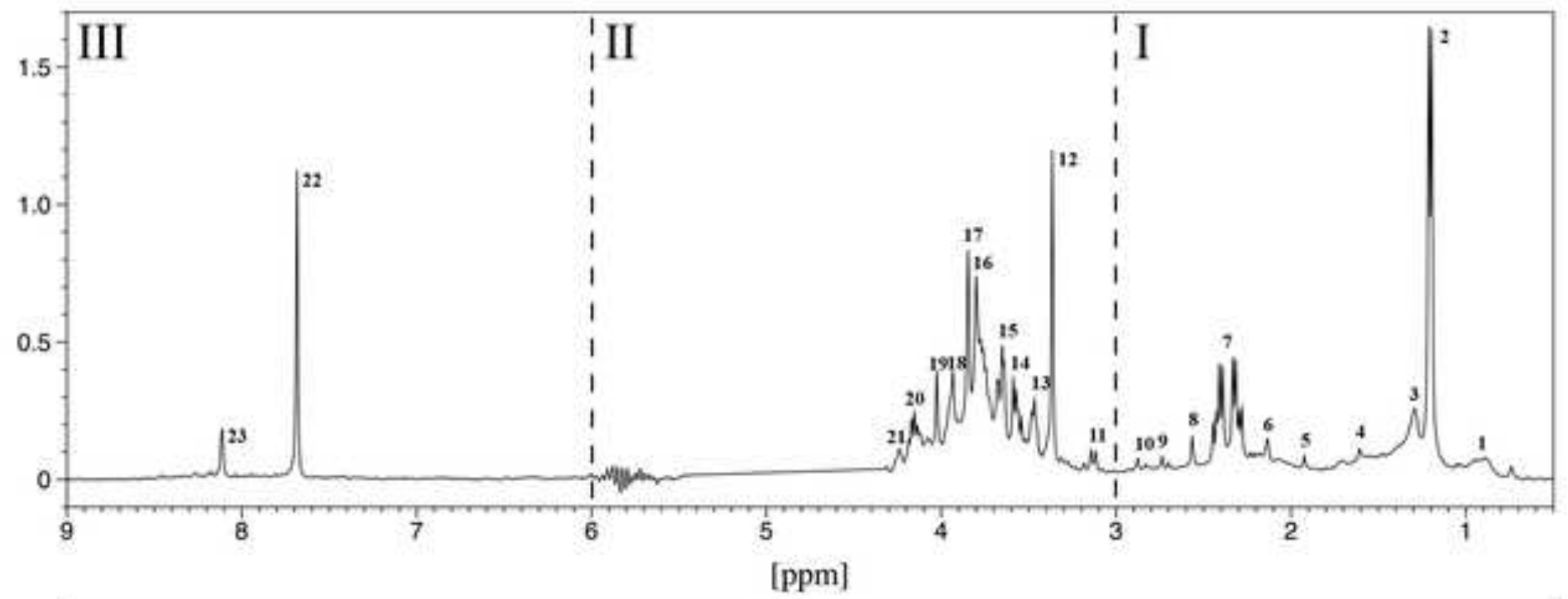

b)

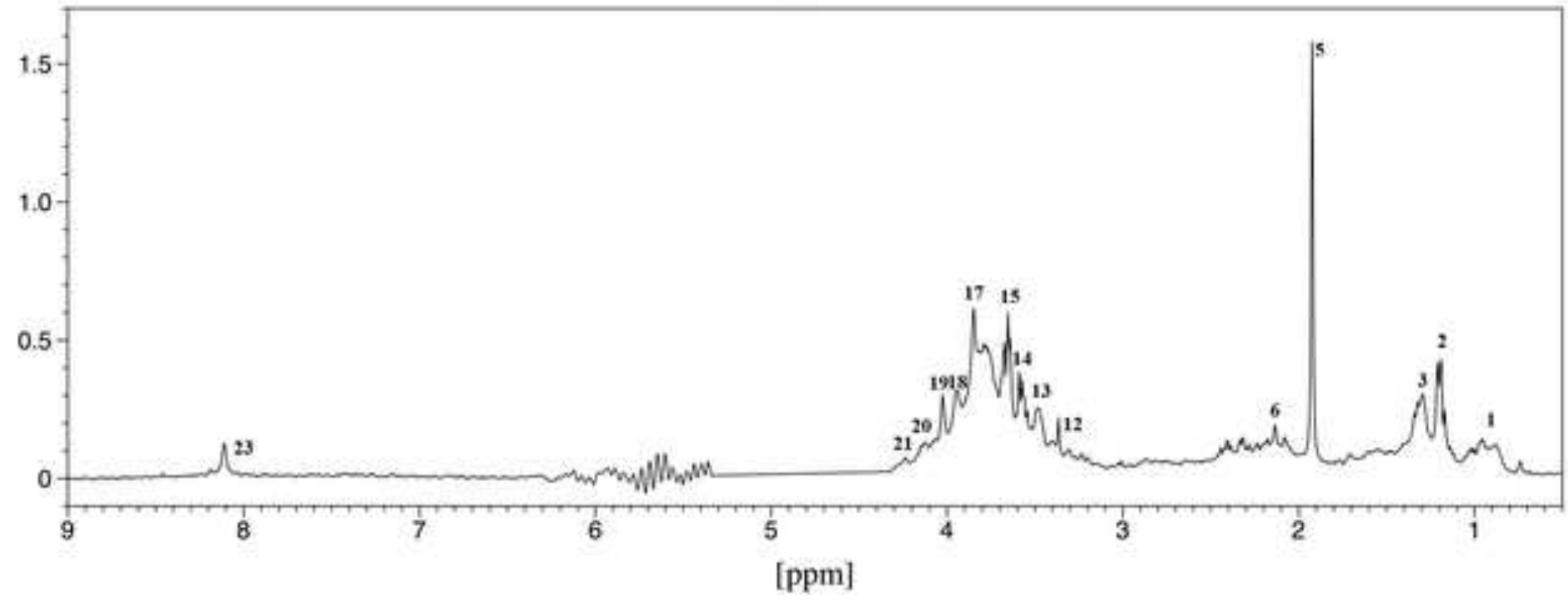


Table 1

\begin{tabular}{|lll|l|l|}
\hline Peak & Compound & $\begin{array}{l}\text { Chemical shifts } \\
(\mathrm{ppm})\end{array}$ & $\mathrm{J}$-value $(\mathrm{Hz})$ & ${ }^{\mathrm{H}} \mathrm{H}$ multiplicity \\
\hline 1 & Leucine/Iseleucine & $0.94\left(-\mathrm{CH}_{3}\right)$ & 0.70 & $\mathrm{~d}$ \\
2 & Lactate & $1.20\left(-\mathrm{CH}_{3}\right)$ & 6.22 & $\mathrm{~d}$ \\
3 & Alanine & $1.30\left(-\mathrm{CH}_{3}\right)$ & 7.02 & $\mathrm{~d}$ \\
4 & Unassigned & 1.61 & - & $\mathrm{s}$ \\
5 & Acetate & $1.95\left(-\mathrm{CH}_{3}\right)$ & - & $\mathrm{s}$ \\
6 & Unassigned & 2.14 & - & $\mathrm{s}$ \\
7 & Malate & 2.317 & nd & $\mathrm{d}$ \\
& & 2.41 & $\mathrm{nd}$ & $\mathrm{d}$ \\
8 & Succinate & $2.56\left(-\mathrm{CH}_{2}\right)$ & - & $\mathrm{s}$ \\
9 & Unassigned & 2.74 & - & $\mathrm{s}$ \\
10 & Unassigned & 2.88 & - & $\mathrm{s}$ \\
\hline 11 & Unassigned & 3.15 & 9.64 & $\mathrm{~d}$ \\
12 & Unassigned & 3.36 & - & $\mathrm{s}$ \\
13 & Unassigned & 3.47 & $\mathrm{nd}$ & $\mathrm{m}$ \\
14 & Glycerol & $3.59\left(-\mathrm{CH}_{2}\right)$ & - & $\mathrm{m}$ \\
15 & Glycerol & $3.65\left(-\mathrm{CH}_{2}\right)$ & - & $\mathrm{s}$ \\
16 & Sugar moiety & 3.80 & - & $\mathrm{s}$ \\
17 & Sugar moiety & 3.85 & - & $\mathrm{s}$ \\
18 & Sugar moiety & 3.93 & - & $\mathrm{s}$ \\
19 & Sugar moiety & 4.02 & - & $\mathrm{nd}$ \\
20 & Unassigned & 4.17 & $\mathrm{nd}$ & $\mathrm{s}$ \\
21 & Unassigned & 4.25 & - & $\mathrm{s}$ \\
\hline 22 & Unassigned & 7.68 & - & $\mathrm{s}$ \\
23 & Formic acid & $8.11\left(-\mathrm{COOH}^{2}\right)$ & - & \\
\hline
\end{tabular}


Table 2

\begin{tabular}{|c|c|c|c|c|c|c|}
\hline Sample and Range & $\begin{array}{c}\mathrm{m} / \mathrm{z} \\
\text { signal }\end{array}$ & To & $\mathrm{To}+\mathrm{Pc}$ & $\mathrm{To}+\mathrm{Mj}$ & $\mathrm{To}+\mathrm{Pc}+\mathrm{Mj}$ & \\
\hline \multirow{5}{*}{$\begin{array}{c}\text { Early } \\
\text { Low Molecular Weight } \\
(70-275 \mathrm{KDa})\end{array}$} & 102 & $5.360 \mathrm{E}+00^{\mathrm{a}}$ & $4.806 \mathrm{E}+00^{\mathrm{a}}$ & $5.822 \mathrm{E}+00^{\mathrm{a}}$ & $8.191 \mathrm{E}+00^{b}$ & + \\
\hline & 113 & $3.478 \mathrm{E}+00^{\mathrm{a}}$ & $2.286 \mathrm{E}+00^{\mathrm{b}}$ & $2.540 \mathrm{E}+00^{\mathrm{b}}$ & $2.628 \mathrm{E}+00^{\mathrm{ab}}$ & - \\
\hline & 130 & $5.591 \mathrm{E}+01^{\mathrm{ac}}$ & $5.406 \mathrm{E}+01^{\mathrm{c}}$ & $6.839 \mathrm{E}+01^{\mathrm{ab}}$ & $7.938 \mathrm{E}+01^{\mathrm{b}}$ & + \\
\hline & $130 \mathrm{~b}$ & $1.993 \mathrm{E}+00^{\mathrm{a}}$ & $1.375 \mathrm{E}+00^{b}$ & $6.870 \mathrm{E}-01^{\mathrm{c}}$ & $8.976 \mathrm{E}-01^{\mathrm{cb}}$ & - \\
\hline & 235 & $5.905 \mathrm{E}+01^{\mathrm{a}}$ & $5.099 \mathrm{E}+01^{\mathrm{ac}}$ & $2.480 \mathrm{E}+01^{\mathrm{b}}$ & $3.582 \mathrm{E}+01^{b c}$ & - \\
\hline \multirow[t]{2}{*}{ Positive mode } & $235 b$ & $4.852 \mathrm{E}+01^{\mathrm{a}}$ & $3.995 \mathrm{E}+01^{\mathrm{a}}$ & $1.551 \mathrm{E}+01^{\mathrm{b}}$ & $2.374 \mathrm{E}+01^{\mathrm{b}}$ & - \\
\hline & 263 & $5.438 \mathrm{E}+00^{\mathrm{a}}$ & $4.176 \mathrm{E}+00^{b}$ & $3.957 \mathrm{E}+00^{b}$ & $4.767 \mathrm{E}+00^{b}$ & - \\
\hline \multicolumn{7}{|l|}{ Early } \\
\hline $\begin{array}{l}\text { Low Molecular Weight } \\
\quad(70-275 \mathrm{KDa})\end{array}$ & 174.8 & $1.176 \mathrm{E}-03^{\mathrm{a}}$ & $2.745 \mathrm{E}-03^{\mathrm{b}}$ & $8.328 \mathrm{E}-04^{\mathrm{a}}$ & $1.145 \mathrm{E}-03^{\mathrm{a}}$ & + \\
\hline \multirow[t]{2}{*}{ Negative mode } & & & & & & \\
\hline & 216.9 & $2.519 \mathrm{E}-03^{\mathrm{ab}}$ & $3.912 \mathrm{E}-03^{\mathrm{a}}$ & $1.731 E-03^{b}$ & $2.156 \mathrm{E}-03^{\mathrm{ab}}$ & - \\
\hline \multirow[t]{2}{*}{ Late } & 86.3 & $1.236 \mathrm{E}+00^{\mathrm{a}}$ & $1.299 \mathrm{E}+00^{\mathrm{a}}$ & $2.945 \mathrm{E}+00^{b}$ & $2.589 \mathrm{E}+00^{b}$ & + \\
\hline & 99.2 & $1.464 \mathrm{E}+00^{\mathrm{a}}$ & $1.544 \mathrm{E}+00^{\mathrm{a}}$ & $1.029 \mathrm{E}+01^{\mathrm{b}}$ & $1.099 \mathrm{E}+01^{\mathrm{b}}$ & + \\
\hline \multirow{4}{*}{$\begin{array}{c}\text { Low Molecular Weight } \\
\text { (70-275KDa) } \\
\text { Positive mode }\end{array}$} & 132.1 & $4.033 \mathrm{E}+00^{\mathrm{a}}$ & $4.571 \mathrm{E}+00^{\mathrm{a}}$ & $1.141 \mathrm{E}+01^{\mathrm{b}}$ & $1.013 E+01^{b}$ & + \\
\hline & 160 & $4.391 \mathrm{E}+00^{\mathrm{a}}$ & $4.724 \mathrm{E}+00^{\mathrm{a}}$ & $1.419 \mathrm{E}+01^{\mathrm{b}}$ & $1.286 \mathrm{E}+01^{\mathrm{b}}$ & + \\
\hline & 235 & $3.033 \mathrm{E}+00^{\mathrm{a}}$ & $3.559 \mathrm{E}+00^{\mathrm{a}}$ & $7.211 \mathrm{E}+00^{\mathrm{b}}$ & $8.861 \mathrm{E}+00^{b}$ & + \\
\hline & $235 b$ & $4.479 \mathrm{E}+01^{\mathrm{a}}$ & $4.001 \mathrm{E}+01^{\mathrm{a}}$ & $7.364 \mathrm{E}+00^{\mathrm{b}}$ & $5.364 \mathrm{E}+00^{\mathrm{b}}$ & - \\
\hline \multirow[t]{2}{*}{ Late } & 79.2 & $3.779 \mathrm{E}-04^{\mathrm{a}}$ & $2.529 \mathrm{E}-04^{\mathrm{a}}$ & $1.159 \mathrm{E}-02^{b}$ & $1.084 \mathrm{E}-02^{\mathrm{b}}$ & + \\
\hline & 89.2 & $3.151 \mathrm{E}-05^{\mathrm{a}}$ & $2.982 \mathrm{E}-05^{\mathrm{a}}$ & $2.578 \mathrm{E}-03^{\mathrm{b}}$ & $2.812 \mathrm{E}-03^{\mathrm{b}}$ & + \\
\hline \multirow{6}{*}{$\begin{array}{c}\text { Low Molecular Weight } \\
\text { (70-275KDa) } \\
\text { Negative mode }\end{array}$} & 132.2 & $9.636 \mathrm{E}-05^{\mathrm{a}}$ & $8.496 \mathrm{E}-05^{\mathrm{a}}$ & $2.765 \mathrm{E}-03^{\mathrm{b}}$ & $3.102 \mathrm{E}-03^{b}$ & + \\
\hline & 148.9 & $4.197 \mathrm{E}-04^{\mathrm{a}}$ & $4.572 \mathrm{E}-04^{\mathrm{a}}$ & $6.417 \mathrm{E}-02^{\mathrm{b}}$ & $7.427 \mathrm{E}-02^{\mathrm{b}}$ & + \\
\hline & 177 & $1.184 \mathrm{E}-03^{\mathrm{a}}$ & $1.163 \mathrm{E}-03^{\mathrm{a}}$ & $6.367 \mathrm{E}-02^{\mathrm{b}}$ & $5.380 \mathrm{E}-02^{\mathrm{b}}$ & + \\
\hline & 194.8 & $4.659 \mathrm{E}-03^{\mathrm{a}}$ & $4.538 \mathrm{E}-03^{\mathrm{a}}$ & $3.370 \mathrm{E}-02^{\mathrm{b}}$ & $2.883 E-02^{b}$ & + \\
\hline & 198.7 & $1.198 \mathrm{E}-03^{\mathrm{a}}$ & $6.976 \mathrm{E}-04^{\mathrm{a}}$ & $1.596 \mathrm{E}-02^{\mathrm{b}}$ & $1.754 \mathrm{E}-02^{\mathrm{b}}$ & + \\
\hline & 216.7 & $1.927 \mathrm{E}-03^{\mathrm{a}}$ & $1.692 \mathrm{E}-03^{\mathrm{a}}$ & $1.194 \mathrm{E}-02^{\mathrm{b}}$ & $1.360 \mathrm{E}-02^{\mathrm{b}}$ & + \\
\hline \multirow{3}{*}{$\begin{array}{c}\text { Early } \\
\text { Medium Molecular } \\
\text { Weight (250-500KDa) } \\
\text { Positive mode }\end{array}$} & 263.1 & $7.411 \mathrm{E}+01^{\mathrm{a}}$ & $7.386 \mathrm{E}+01^{\mathrm{a}}$ & $7.250 \mathrm{E}+01^{\mathrm{a}}$ & $9.324 \mathrm{E}+01^{\mathrm{b}}$ & + \\
\hline & 345.2 & $2.400 \mathrm{E}+01^{\mathrm{a}}$ & $1.680 \mathrm{E}+01^{\mathrm{bc}}$ & $1.449 \mathrm{E}+01^{\mathrm{c}}$ & $2.000 \mathrm{E}+01^{\mathrm{ab}}$ & - \\
\hline & 382 & $1.270 \mathrm{E}+01^{\mathrm{a}}$ & $9.935 \mathrm{E}+00^{\mathrm{b}}$ & $8.756 \mathrm{E}+00^{b}$ & $1.059 \mathrm{E}+01^{\mathrm{ab}}$ & - \\
\hline \multirow{4}{*}{$\begin{array}{c}\text { Early } \\
\text { Medium Molecular } \\
\text { Weight }(250-500 \mathrm{KDa}) \\
\text { Negative mode }\end{array}$} & 261.1 & $2.140 \mathrm{E}-02^{\mathrm{a}}$ & $2.438 \mathrm{E}-02^{\mathrm{a}}$ & $4.012 \mathrm{E}-02^{b}$ & $2.470 \mathrm{E}-02^{\mathrm{a}}$ & + \\
\hline & 315.5 & $2.803 \mathrm{E}-03^{\mathrm{a}}$ & $3.131 \mathrm{E}-03^{\mathrm{a}}$ & $3.794 \mathrm{E}-03^{\mathrm{a}}$ & $6.541 \mathrm{E}-03^{\mathrm{b}}$ & + \\
\hline & 343.9 & $5.254 \mathrm{E}-02^{\mathrm{a}}$ & $2.881 \mathrm{E}-02^{\mathrm{ab}}$ & $2.310 \mathrm{E}-02^{\mathrm{b}}$ & $1.062 \mathrm{E}-02^{\mathrm{b}}$ & - \\
\hline & 431.1 & $1.742 \mathrm{E}-04^{\mathrm{a}}$ & $2.175 \mathrm{E}-04^{\mathrm{ab}}$ & $2.201 \mathrm{E}-04^{\mathrm{ab}}$ & $2.755 \mathrm{E}-04^{b}$ & + \\
\hline \multirow{4}{*}{$\begin{array}{c}\text { Late } \\
\text { Medium Molecular } \\
\text { Weight (250-500KDa) } \\
\text { Positive mode }\end{array}$} & 293.1 & $1.402 \mathrm{E}+01^{\mathrm{a}}$ & $1.366 \mathrm{E}+01^{\mathrm{a}}$ & $7.233 \mathrm{E}+01^{b}$ & $8.386 \mathrm{E}+01^{\mathrm{c}}$ & + \\
\hline & 325 & $1.354 \mathrm{E}+00^{\mathrm{a}}$ & $1.275 \mathrm{E}+00^{\mathrm{ab}}$ & $1.196 \mathrm{E}+00^{b}$ & $1.137 \mathrm{E}+00^{b}$ & - \\
\hline & 382 & $1.114 \mathrm{E}+01^{\mathrm{a}}$ & $1.154 \mathrm{E}+01^{\mathrm{a}}$ & $2.315 \mathrm{E}+00^{\mathrm{b}}$ & $2.518 \mathrm{E}+00^{b}$ & - \\
\hline & 384 & $6.491 \mathrm{E}+00^{\mathrm{a}}$ & $6.552 \mathrm{E}+00^{\mathrm{a}}$ & $2.017 \mathrm{E}+00^{\mathrm{b}}$ & $2.382 \mathrm{E}+00^{b}$ & - \\
\hline \multirow{4}{*}{$\begin{array}{c}\text { Late } \\
\text { Medium Molecular } \\
\text { Weight (250-500KDa) }\end{array}$} & 256.7 & $8.386 \mathrm{E}+01^{\mathrm{a}}$ & $9.560 \mathrm{E}+01^{\mathrm{a}}$ & $1.863 \mathrm{E}+00^{b}$ & $1.724 \mathrm{E}+00^{b}$ & - \\
\hline & 286.1 & $9.219 \mathrm{E}+01^{\mathrm{a}}$ & $8.685 \mathrm{E}+01^{\mathrm{a}}$ & $4.417 \mathrm{E}+01^{b}$ & $4.744 \mathrm{E}+01^{\mathrm{b}}$ & - \\
\hline & 300 & $7.452 \mathrm{E}+00^{\mathrm{a}}$ & $6.886 \mathrm{E}+00^{\mathrm{a}}$ & $1.459 \mathrm{E}+00^{b}$ & $1.722 \mathrm{E}+00^{\mathrm{b}}$ & - \\
\hline & 339 & $8.570 \mathrm{E}-01^{\mathrm{a}}$ & $7.299 \mathrm{E}-01^{\mathrm{a}}$ & $3.311 \mathrm{E}+00^{\mathrm{b}}$ & $3.246 \mathrm{E}+00^{\mathrm{b}}$ & + \\
\hline \multirow[t]{3}{*}{ Negative mode } & 343 & $9.582 \mathrm{E}+01^{\mathrm{a}}$ & $9.230 \mathrm{E}+01^{\mathrm{a}}$ & $9.475 \mathrm{E}+00^{b}$ & $1.229 \mathrm{E}+01^{\mathrm{b}}$ & - \\
\hline & 360.8 & $6.666 \mathrm{E}+00^{\mathrm{a}}$ & $7.073 \mathrm{E}+00^{\mathrm{a}}$ & 8.123E-01 ${ }^{b}$ & 8.085E-01 ${ }^{b}$ & - \\
\hline & 385.5 & $1.760 \mathrm{E}+01^{\mathrm{a}}$ & $7.456 \mathrm{E}+00^{\mathrm{a}}$ & $4.211 \mathrm{E}+01^{\mathrm{b}}$ & $4.787 \mathrm{E}+01^{b}$ & + \\
\hline
\end{tabular}

